\title{
Treatment of congestion in upper respiratory diseases
}

This article was published in the following Dove Press journal:

International Journal of General Medicine

15 February 2010

Number of times this article has been viewed

\author{
Eli O Meltzer ${ }^{\prime}$ \\ Fernan Caballero ${ }^{2}$ \\ Leonard M Fromer ${ }^{3}$ \\ John H Krouse 4 \\ Glenis Scadding ${ }^{5}$ \\ 'Allergy and Asthma Medical Group \\ and Research Center, San Diego, \\ CA and Department of Pediatrics, \\ University of California, San Diego, \\ USA; ${ }^{2}$ Allergy and Clinical Immunology \\ Service, Centro Medico-Docente La \\ Trinidad, Caracas, Venezuela; ${ }^{3}$ David \\ Geffen School of Medicine, University \\ of California, Los Angeles, USA; ${ }^{4}$ Wayne \\ State University School of Medicine, \\ Detroit, Michigan, USA; ${ }^{5}$ Department \\ of Allergy and Rhinology, Royal \\ National TNE Hospital, London, UK
}

Correspondence: Eli O Meltzer Allergy and Asthma Medical Group and Research Center, 9610 Granite Ridge Drive, Suite B, San Diego, CA, 92123 , USA Tel + I 858-292-2368 $\times 157$

Fax +1 858-268-5|47

Email eomeltzer@aol.com

\begin{abstract}
Congestion, as a symptom of upper respiratory tract diseases including seasonal and perennial allergic rhinitis, acute and chronic rhinosinusitis, and nasal polyposis, is principally caused by mucosal inflammation. Though effective pharmacotherapy options exist, no agent is universally efficacious; therapeutic decisions must account for individual patient preferences. Oral $\mathrm{H}_{1}$-antihistamines, though effective for the common symptoms of allergic rhinitis, have modest decongestant action, as do leukotriene receptor antagonists. Intranasal antihistamines appear to improve congestion better than oral forms. Topical decongestants reduce congestion associated with allergic rhinitis, but local adverse effects make them unsuitable for long-term use. Oral decongestants show some efficacy against congestion in allergic rhinitis and the common cold, and can be combined with oral antihistamines. Intranasal corticosteroids have broad anti-inflammatory activities, are the most potent long-term pharmacologic treatment of congestion associated with allergic rhinitis, and show some congestion relief in rhinosinusitis and nasal polyposis. Immunotherapy and surgery may be used in some cases refractory to pharmacotherapy. Steps in congestion management include (1) diagnosis of the cause(s), (2) patient education and monitoring, (3) avoidance of environmental triggers where possible, (4) pharmacotherapy, and (5) immunotherapy (for patients with allergic rhinitis) or surgery for patients whose condition is otherwise uncontrolled.
\end{abstract}

Keywords: allergic rhinitis, congestion, obstruction, rhinosinusitis, treatment

\section{Introduction}

Congestion, which may be best described as a feeling of blockage, fullness, or restricted airflow, is a primary symptom of common upper respiratory tract disorders, including allergic rhinitis, acute rhinosinusitis, chronic rhinosinusitis, and nasal polyposis. Congestion impacts negatively on patient quality of life by interfering with both sleep and daytime activities. In allergic rhinitis, it is the symptom patients find most bothersome and would like most to prevent. ${ }^{1,2}$ Congestion may also exert secondary effects on the paranasal sinuses, ears, throat, voice, and chest that manifest as irritated throat, headaches, impairment in hearing, reduced ability to smell, worsening of asthma, problematic snoring, and disturbance of sleep. ${ }^{2}$

The principal underlying cause of nasal congestion in common upper airway disorders in adults is inflammation, which usually manifests as venous engorgement, increased nasal secretions, and tissue swelling/edema that ultimately leads to impaired airflow and the sensation of nasal blockage. Consequently, development of pharmacologic therapies for congestion in these diseases has been guided by the need to target underlying pathophysiologic mechanisms including inflammation 
(ie, anti-inflammatory activity of intranasal corticosteroids) and its manifestations such as venous engorgement (ie, vasoconstrictive action of decongestants). It is important to note that the perception of congestion in chronic rhinosinusitis can also be caused by polyps extruding into the nasal airway, producing a physical obstruction in the nostrils.

The pervasiveness of allergic rhinitis ${ }^{3}$ and rhinosinusitis ${ }^{4,5}$ has caused congestion to become a highly prevalent problem, even when less common causes are excluded. In addition, the upper airway respiratory diseases in which congestion is a common symptom (ie, allergic rhinitis, nonallergic/vasomotor rhinitis, rhinosinusitis, nasal polyposis, and the common cold) are undertreated due to the lack of efficacy with some current therapies ${ }^{6-8}$ and safety concerns with others..$^{6,9,10}$ Thus, there remains a large unmet clinical need for options for congestion, and further study and more effective therapies are necessary to improve treatment. This review covers treatment considerations for congestion associated with the common upper airway diseases described above. Also presented is a brief overview of treatments for some of the less common rhinopathies, as well as surgical options for congestion due to mechanical abnormalities and treatment-resistant chronic rhinosinusitis.

\section{Treatment considerations}

A stepwise approach is recommended for the management and treatment of nasal congestion. The 5 main principles are (1) diagnosis of the cause(s), (2) patient education and monitoring, (3) avoidance of environmental trigger factors where possible, (4) pharmacotherapy, and (5) allergen immunotherapy (only in patients with allergic rhinitis with documented sensitivity to specific allergens) or surgery for patients in whom the condition cannot be controlled with the previous measures. ${ }^{11}$

Patient education should involve the patient, family members, and any caregivers. Ideally it should begin at the time of diagnosis and continue throughout clinical care. Education of the patient should include an explanation of the condition and a definition of therapeutic goals. The physician should inquire about the patient's concerns and preferences for various interventions and discuss potential side effects of treatment. ${ }^{12}$ Effective disease management should include a regular review of the treatment goals and monitoring of patient progress, including treatment adherence.

Once a diagnosis has been established, environmental triggers that may contribute to congestion should be avoided when possible. These triggers include allergens (eg, pollen, dust mites, animal dander, mold spores, cockroach droppings), irritants (eg, smoke, fumes, strong odors), and infectious agents. ${ }^{13}$ Environmental controls need to be tailored to the individual patient's exposures and sensitivities. Unfortunately, such controls are not always practical, effective, or indicated, and thus supplemental medical treatment is often required. ${ }^{1}$ For allergen exposure, environmental adjustments that have demonstrated efficacy include trigger avoidance, low indoor humidity (below 50\%), allergen-proof pillows and mattress covers, minimizing carpeting, and minimizing fur-bearing pet contact. ${ }^{13,14}$ Although a high-efficiency particulate air (HEPA) vacuum filter may reduce animal and dust mite allergen exposure, the evidence of its effectiveness in alleviating symptoms is not conclusive. Vacuuming of rugs is not effective in decreasing animal allergens, because it only eliminates superficial areas and does not clean the deeper levels of the rug. ${ }^{13}$ For irritants related to employment, appropriate control measures (eg, fume hoods, positive pressure ventilation, air filtration, self-contained breathing units) should be implemented.

When developing a strategy for the pharmacologic treatment of nasal congestion, a physician should consider a number of factors, including the underlying etiology of the condition, likely pathophysiology and dominant symptom(s). The efficacy and safety of possible drug choices should be weighed against specific patient characteristics such as comorbid airway disorders, age, appropriateness of drug formulations, patient preference, prior and current therapy, and compliance history. ${ }^{12}$ In a 2005 survey of 783 allergy medication users conducted by the Gallup Organization, respondents were asked which drug characteristics were most important to them. The most important properties to patients were: specifically targets individual symptoms (86\%), fast onset of action (81\%), few adverse events (79\%), nonhabit forming (77\%), and long duration of action $(77 \%){ }^{15}$

Creating a collaborative partnership with patients and their families will help improve adherence. Clinical decisions should not only be made on the basis of the best available evidence but should also be consistent with patients' expectations, preferences, goals, and capabilities. Patient adherence and compliance may also be affected by access to medications, including issues of product or formulation availability and cost. Important factors in improving patient adherence also include the selection of medications most appropriate to the patient's clinical profile, avoidance of problems associated with past treatment, and appraisal of any new medications' product attributes to determine if they align with the patient's preferences. Patients should be instructed on the correct way 
to use medication and encouraged to ask questions. Patient satisfaction with treatment should also be included in the process of follow-up and monitoring.

Medications that have been extensively evaluated in adequately designed clinical trials for the treatment of congestion associated with various upper respiratory disorders include oral and intranasal antihistamines, leukotriene receptor antagonists, oral and intranasal decongestants, and intranasal corticosteroids. ${ }^{67,11}$ Other therapies such as intranasal cromones, ${ }^{6}$ topical lysine aspirin, ${ }^{16}$ topical anticholinergics, ${ }^{6}$ systemic corticosteroids, ${ }^{11}$ capsaicin, ${ }^{17,18}$ menthol,,${ }^{19}$ and nasal douching ${ }^{6}$ have also been used for treatment of congestion, mostly in patients with rhinitis, but their ability to provide congestion relief has not been unequivocally demonstrated.

In patients with congestion due to allergic rhinitis, immunotherapy may be considered when previous options have proven insufficient to control symptoms. Immunotherapy has demonstrated efficacy against congestion and is the only intervention for allergic rhinitis that alters the natural history of the disease. ${ }^{20}$

\section{Pharmacologic therapy for congestion}

\section{Antihistamines}

$\mathrm{H}_{1}$-antihistamines exert their antiallergic effects by inhibiting the binding of histamine, an important mediator of allergic response, to the $\mathrm{H}_{1}$ histamine receptor. ${ }^{6}$ First-generation oral $\mathrm{H}_{1}$-antihistamines, such as chlorpheniramine, diphenhydramine, and triprolidine, are associated with marked sedation, whereas the more recently introduced second-generation oral $\mathrm{H}_{1}$-antihistamines, including acrivastine, astemizole, azelastine, cetirizine, desloratadine, ebastine, fexofenadine, levocetirizine, loratadine, mizolastine, and terfenadine, have a more favorable benefit-to-risk profile (some of these agents are available only in Europe). ${ }^{6,10}$ Intranasal antihistamines include azelastine, levocabastine, and olopatadine. .,10,21 $^{2}$

Although oral and intranasal $\mathrm{H}_{1}$-antihistamines have demonstrated efficacy against nasal congestion in patients with allergic rhinitis, ${ }^{10,22}$ the magnitude of benefit is relatively modest and less pronounced than that observed with decongestants or intranasal steroids. ${ }^{10,23-28}$ Some improvement in congestion with oral and/or intranasal $\mathrm{H}_{1}$-antihistamines has also been reported in patients with nonallergic/vasomotor rhinitis, ${ }^{29,30}$ rhinosinusitis, ${ }^{31}$ and nasal polyposis, ${ }^{32,33}$ whereas no effect on congestion was evident in studies of $\mathrm{H}_{1}$-antihistamines in patients with the common cold. ${ }^{34-36}$ Key features of antihistamines include convenient oral or intranasal administration (in many cases, once daily), rapid onset of symptom relief, and good overall safety and tolerability profile.

\section{Congestion efficacy in allergic rhinitis \\ Oral antihistamines}

A recent meta-analysis of studies with oral $\mathrm{H}_{1}$-antihistamines in allergic rhinitis has demonstrated significant improvements in both patient-rated and physician-rated congestion. ${ }^{22}$ However, compared with their efficacy against other nasal symptoms associated with allergic rhinitis (eg, nasal itching, sneezing, rhinorrhea), oral (and intranasal) $\mathrm{H}_{1}$-antihistamines appear to be less effective for relief of congestion/obstruction. ${ }^{6,10} \mathrm{Nev}$ ertheless, in clinical trials with various agents, both oral and intranasal antihistamines have demonstrated some congestion relief in patients with allergic rhinitis.

A placebo-controlled study of patients with seasonal allergic rhinitis reported that oral acrivastine $4 \mathrm{mg}$ twice daily and $8 \mathrm{mg}$ twice daily led to significant reductions in total symptom score, sneezing and runny nose, but the improvements in congestion did not achieve statistical significance. ${ }^{37}$ In a placebo-controlled trial with terfenadine $60 \mathrm{mg}$ twice daily and astemizole $10 \mathrm{mg}$ once daily in patients with seasonal allergic rhinitis, astemizole showed superior relief of sneezing and runny nose versus both placebo and terfenadine, but the congestion scores with either antihistamine were not superior to placebo. ${ }^{38}$ Oral azelastine has demonstrated efficacy against nasal symptoms of perennial allergic rhinitis, but the improvement in congestion was only modest and did not achieve statistical significance at either the 1-mg twice daily or the 2-mg twice daily dose level. ${ }^{39}$ Studies with ebastine $10 \mathrm{mg}$ and $20 \mathrm{mg}$ in seasonal and perennial allergic rhinitis ${ }^{40,41}$ have also demonstrated some congestion relief versus placebo, but the improvement in congestion in patients with perennial allergic rhinitis failed to reach statistical significance with either dose. ${ }^{40}$ Mizolastine therapy in patients with perennial allergic rhinitis also reduced congestion score after 4 weeks of treatment, but the improvement over placebo was not statistically significant. ${ }^{42}$

Some of the most extensively evaluated secondgeneration oral $\mathrm{H}_{1}$-antihistamines in allergic rhinitis include loratadine, fexofenadine, cetirizine, desloratadine, and levocetirizine. In a study of adults with seasonal allergic rhinitis, loratadine was associated with greater improvements in nasal stuffiness score at day 4 and overall versus placebo, although the differences were not statistically significant for either comparison. ${ }^{24} \mathrm{~A} 4$-week trial in adults with perennial allergic rhinitis showed that loratadine $10 \mathrm{mg}$ once daily and 
terfenadine $60 \mathrm{mg}$ twice daily both significantly reduced nasal stuffiness compared with placebo. ${ }^{43} \mathrm{~A}$ pooled analysis of 3 studies in children with seasonal allergic rhinitis showed that fexofenadine $30 \mathrm{mg}$ twice daily significantly reduced all nasal symptoms versus placebo, including congestion, ${ }^{44}$ and a separate study in adults with seasonal allergic rhinitis reported that fexofenadine $120 \mathrm{mg}$ once daily for 2 weeks significantly reduced nasal congestion score versus placebo. ${ }^{45}$ In a small study of 31 patients with perennial allergic rhinitis, fexofenadine $120 \mathrm{mg}$ once daily and $180 \mathrm{mg}$ once daily both significantly decreased nasal congestion from baseline beginning 1 week after treatment and persisting until the end of 4 weeks of treatment, in contrast to the absence of significant reduction with placebo. ${ }^{46}$ However, fexofenadine is not approved for treatment of perennial allergic rhinitis in either the United States or Europe. A 2-week placebocontrolled trial in adults with seasonal allergic rhinitis demonstrated significant improvements in congestion with both fexofenadine (120 mg once daily and $180 \mathrm{mg}$ once daily) and cetirizine $10 \mathrm{mg}$ once daily, but the magnitudes of improvement were less pronounced than for other nasal symptoms. ${ }^{47}$ In a 4 -week study in adults with perennial allergic rhinitis, improvement in congestion with cetirizine $10 \mathrm{mg}$ once daily and $20 \mathrm{mg}$ once daily was also greater than that observed with placebo, although the reductions in other nasal symptoms, most notably postnasal discharge and sneezing, were greater. ${ }^{48}$ In adults with intermittent allergic rhinitis, 2 weeks of therapy with desloratadine $5 \mathrm{mg}$ once daily significantly reduced nasal congestion versus placebo at all time points evaluated. ${ }^{49}$ In patients with perennial allergic rhinitis, desloratadine $5 \mathrm{mg}$ once daily significantly reduced all nasal symptoms with the exception of congestion over the 4-week treatment period. ${ }^{50}$ Treatment of adult patients with seasonal allergic rhinitis with 3 different dosing regimens of levocetirizine (2.5 mg once daily, $5 \mathrm{mg}$ once daily, and $10 \mathrm{mg}$ once daily) for 2 weeks failed to significantly improve nasal congestion versus placebo despite superior efficacy on other nasal symptoms. ${ }^{51}$ In adults with persistent allergic rhinitis, therapy with levocetirizine $5 \mathrm{mg}$ once daily was associated with a nonsignificant trend toward greater reduction in nasal congestion versus placebo at weeks 1 or 4 , and the reduction achieved statistical significance after 6 months of treatment. ${ }^{52}$

\section{Intranasal antihistamines}

In general, clinical trials with intranasal antihistamines have demonstrated some efficacy against nasal congestion in allergic rhinitis compared with placebo, although no meta-analyses of studies with different agents have been published to date. Intranasal azelastine twice daily for 2 weeks reduced nasal congestion in adults with seasonal allergic rhinitis significantly more than oral cetirizine $10 \mathrm{mg}$ once daily. In an 8-week study in adults with perennial allergic rhinitis, intranasal azelastine failed to significantly reduce congestion versus placebo, in contrast to a significant reduction in congestion versus placebo reported with the intranasal steroid flunisolide. ${ }^{53}$ A 6-week trial in adults with seasonal allergic rhinitis showed minimal improvement in congestion-free days with intranasal levocabastine over placebo, whereas a significant improvement in congestion-free days versus placebo was observed with intranasal fluticasone propionate. ${ }^{54}$ A separate 4 -week trial in adults with seasonal allergic rhinitis reported inferior all-day congestion relief with intranasal levocabastine compared with mometasone furoate nasal spray. ${ }^{55}$ Intranasal olopatadine therapy for 2 weeks in adults with seasonal allergic rhinitis was associated with significant congestion relief compared with placebo in one study. ${ }^{56}$ But the reduction in congestion reported in a separate trial in adults with seasonal allergic rhinitis did not achieve statistical significance. ${ }^{57}$

\section{Congestion efficacy in nonallergic/ vasomotor rhinitis}

Only one study evaluated the effect of an oral antihistamine on congestion exclusively in patients with nonallergic rhinitis, although it is difficult to discern its effect because it was given in combination with an intranasal steroid. In that study, the addition of oral loratadine to intranasal flunisolide resulted in greater improvements in sneezing and rhinorrhea compared with flunisolide alone, but did not improve congestion. ${ }^{30}$ In a population of patients with perennial allergic and nonallergic rhinitis, oral astemizole had a marginal effect on nasal congestion, in contrast to a significant improvement in congestion observed with intranasal steroid beclomethasone dipropionate. ${ }^{58}$

In a 2-week study in patients with vasomotor rhinitis, intranasal azelastine significantly reduced congestion at 15 days, but the improvement reported at 8 days was not statistically significant. ${ }^{59}$ Some improvement of congestion with intranasal azelastine in patients with vasomotor rhinitis was also reported in another trial, although the effect was not consistently significant. ${ }^{29} \mathrm{~A}$ trial in patients with allergic and nonallergic disease, including symptoms of nasal obstruction, found no consistent benefit of intranasal levocabastine over placebo on nasal obstruction, and the intranasal steroid beclomethasone dipropionate was shown to be superior to levocabastine for nasal obstruction relief. ${ }^{60}$ 


\section{Congestion efficacy in rhinosinusitis}

Only one study reported the effect of an oral antihistamine on nasal congestion in patients with acute rhinosinusitis. This study demonstrated that, in patients with allergic rhinitis experiencing acute exacerbations of rhinosinusitis, loratadine significantly improved nasal obstruction compared with placebo after 28 days of treatment. ${ }^{31}$

\section{Congestion efficacy in nasal polyposis}

The only published study of oral antihistamine efficacy on congestion in nasal polyposis was conducted in patients with residual or recurrent nasal polyposis after ethmoidectomy who were treated with either cetirizine at twice the daily recommended $\left(20 \mathrm{mg}\right.$ ) dose or placebo for 3 months. ${ }^{32}$ The percentage of days with nasal obstruction score $\leq 1$ (on a scale from 0 [no discomfort] to 3 [severe discomfort]) at weeks 4 and 8 in the cetirizine and placebo groups was similar, while patients treated with cetirizine had significantly more such days than placebo-treated patients at week $12 .{ }^{32} \mathrm{In}$ the only trial of an intranasal antihistamine in patients with nasal polyps (and perennial allergic rhinitis), postsurgery treatment with azelastine nasal spray $(0.14 \mathrm{mg}$ to each nostril twice daily) had no consistent effect on nasal obstruction over a 25 -week treatment period. ${ }^{33}$

\section{Congestion efficacy in the common cold}

In a trial in patients with the common cold, the reduction in congestion after 4 days of treatment with terfenadine $120 \mathrm{mg}$ twice daily for 4 to 5 days was similar to that reported with placebo. ${ }^{34} \mathrm{~A}$ separate study in adults with the common cold reported that the combination of an oral antihistamine and decongestant (loratadine and pseudoephedrine) resulted in significant relief of patient-reported nasal stuffiness on days 1 to 5 of treatment compared with placebo, ${ }^{61}$ but the effect attributable to the antihistamine could not be differentiated from that of the decongestant. In contrast, 2 other studies in patients with the common cold did not show a significant improvement in congestion with the combination of an antihistamine and a decongestant. ${ }^{62,63}$

\section{Safety}

The use of first-generation antihistamines (eg, diphenhydramine, brompheniramine, chlorpheniramine) is associated with a number of adverse central nervous system (CNS) sedation effects, including somnolence and performance impairment. ${ }^{12}$ Other side effects of the older agents include anticholinergic effects, such as dryness of the mouth, urinary retention, and blurred vision. ${ }^{12}$ The newer
$\mathrm{H}_{1}$-antihistamines, including cetirizine, desloratadine, fexofenadine, levocetirizine, and loratadine, are preferred to older agents because they have similar $\mathrm{H}_{1}$-receptor inverse agonist activity compared but are consistently less sedating, presumably due to reduced CNS penetration. ${ }^{64}$

In summary, clinical evidence suggests that antihistamines are, at best, a modestly effective therapy for congestion associated with allergic rhinitis. However, their decongestant action is generally insufficient and inferior to that of intranasal steroids. Antihistamines may also provide some congestion relief in nonallergic upper respiratory diseases, although the supporting evidence is limited. From a safety standpoint, second-generation oral antihistamines are preferred over earlier agents because of an improved safety profile, although somnolence and performance impairment have also been reported with some of them.

\section{Leukotriene receptor antagonists}

Leukotrienes are contributing mediators of nasal allergic reactions, and their presence in the nose may lead to nasal obstruction. ${ }^{6}$ Therefore, a pharmacologic agent that inhibits the effects of leukotrienes might offer relief of symptomatic nasal congestion. Leukotriene receptor antagonists zafirlukast and montelukast have receptor affinities that are approximately 2 times greater than that of the natural ligand LTD $4,{ }^{6}$ which may enhance their clinical efficacy. Leukotriene receptor antagonists have demonstrated some efficacy against nasal congestion in allergic rhinitis and rhinosinusitis, although they appear to be inferior to intranasal steroids in this regard.

\section{Congestion efficacy in allergic rhinitis}

A meta-analysis of 6 placebo-controlled trials in patients with allergic rhinitis demonstrated that leukotriene receptor antagonists significantly reduce total nasal symptoms versus placebo, but the effect on congestion or other individual symptoms was not reported. ${ }^{65}$ While several small studies have evaluated the efficacy of zafirlukast ${ }^{66,67}$ and zileuton ${ }^{68}$ in patients with allergic rhinitis, montelukast has been the only leukotriene receptor antagonist studied in large trials in these patients. A study in 1302 patients with seasonal allergic rhinitis found that both montelukast and the antihistamine loratadine produced a modest decongestant effect after 2 weeks of treatment, with greater effects on other nasal symptoms. ${ }^{69}$ The combination of loratadine plus montelukast was found to be significantly more effective than either therapy alone for daytime nasal symptoms in patients with seasonal allergic rhinitis, although the effect on congestion was not significantly different 
from montelukast alone. ${ }^{70}$ Moinuddin et al reported that the combination of loratadine and montelukast administered for 2 weeks significantly improved peak nasal inspiratory flow in patients with seasonal allergic rhinitis, with the effect comparable to treatment with fexofenadine and pseudoephedrine. ${ }^{71}$ In a study of 1992 adults with perennial allergic rhinitis, 6 weeks of treatment with montelukast achieved a significantly greater improvement in all daytime nasal symptoms, including congestion, than placebo, although the study may have been overpowered (Figure 1). ${ }^{72}$

Several studies have documented that the congestion relief with leukotriene receptor antagonists is inferior to that achieved with intranasal steroids..$^{8,73,74}$ In addition, the combination of leukotriene receptor antagonists and $\mathrm{H}_{1}$-antihistamines has also been shown to provide significantly less effective congestion relief than intranasal steroids. ${ }^{65}$

\section{Congestion efficacy in nonallergic/ vasomotor rhinitis}

There are no published reports on the efficacy of leukotriene receptor antagonists for relief of congestion associated with nonallergic/vasomotor rhinitis.

\section{Congestion efficacy in rhinosinusitis and/or nasal polyposis}

Antileukotrienes have not been adequately studied for the treatment of congestion associated with rhinosinusitis or nasal polyposis. ${ }^{7}$ In a small study of 40 patients who underwent surgery for nasal polyps, postoperative therapy with montelukast was significantly less effective than intranasal beclomethasone for congestion relief over 12 months. ${ }^{75}$

\section{Congestion efficacy in the common cold}

No studies have been published on the efficacy of leukotriene receptor antagonists for relief of congestion associated with the common cold.

\section{Congestion efficacy in aspirin \\ triad disease}

A small retrospective analysis reported the effect of antileukotriene therapy (zarfirlukast or zileuton) for relief of congestion in patients with aspirin triad disease who had persistent chronic rhinosinusitis despite previous paranasal sinus surgery. ${ }^{76}$ Patient self-reports showed significant improvement in congestion and other major and minor symptoms, which was consistent with the findings of endoscopic nasal exams. ${ }^{76}$

\section{Safety}

Pediatric studies have demonstrated that montelukast is well-tolerated, with the majority of adverse events, including headache, ear infection, nausea, abdominal pain, and pharyngitis, being mild. ${ }^{77}$ The incidence of these adverse events with montelukast does not appear to be higher than with placebo. ${ }^{78}$ No dose adjustment with montelukast is necessary for patients with renal or mild-to-moderate hepatic dysfunction. ${ }^{79}$

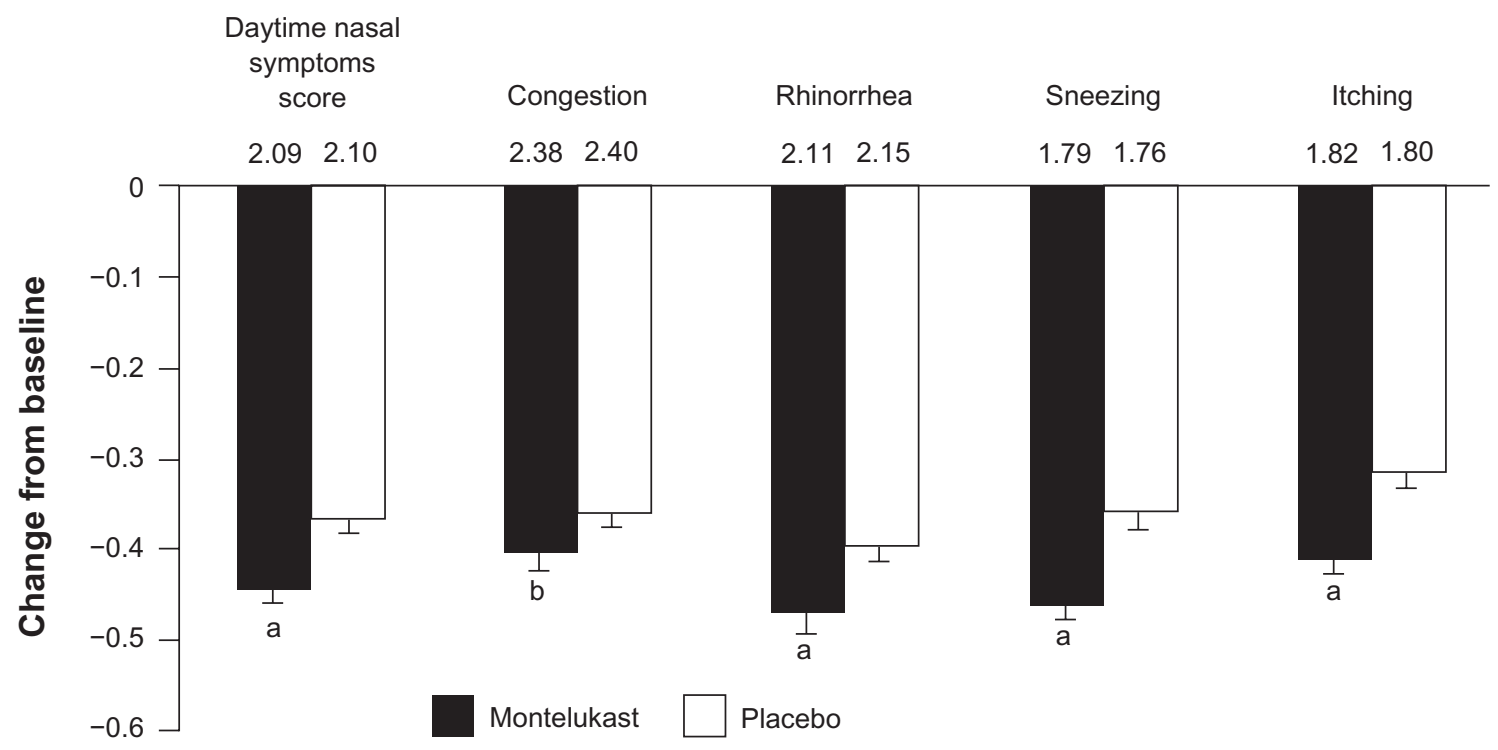

Figure I Least squares mean change in the composite daytime nasal symptoms score and its components during a 6-week trial of montelukast versus placebo in patients with perennial allergic rhinitis. Baseline scores are shown above the bars. ${ }^{a} P<0.001$; ${ }^{b} P<0.05$. Error bars represent SE. Reproduced with permission from Patel P, Philip G, Yang W, et al Randomized, double-blind, placebo-controlled study of montelukast for treating perennial allergic rhinitis. Ann Allergy Asthma Immunol. 2005; 95 (6):55I-557.72 Copyright $@($ 2005 American College of Allergy, Asthma and Immunology. 
Recently, the Food and Drug Administration (FDA) published reports of neuropsychiatric events associated with the use of montelukast and other antileukotrienes, including postmarket cases of agitation, aggression, anxiousness, dream abnormalities and hallucinations, depression, insomnia, suicidal thinking and behavior, and tremor. The FDA recommended remaining alert for such events and considering discontinuation of medication if these symptoms develop. ${ }^{80}$ Isolated reports of Churg-Strauss syndrome, a rare systemic vasculitis associated with asthma, have been described in asthma patients treated with montelukast; a causal relationship has not been established. ${ }^{81}$

In summary, the leukotriene receptor antagonist montelukast has demonstrated some efficacy against nasal congestion in allergic rhinitis. Its decongestant effects, both alone and in combination with an $\mathrm{H}_{1}$-antihistamine, are inferior to that observed with intranasal corticosteroids. The congestion efficacy of other leukotriene receptor antagonists (eg, zafirlukast, zileuton, pranlukast) in allergic rhinitis and other upper respiratory disorders (ie, nonallergic/vasomotor rhinitis, rhinosinusitis, nasal polyposis, and the common cold) have not been adequately evaluated to date. The overall safety profile of leukotriene receptor antagonists is good.

\section{Decongestants}

Decongestants improve nasal ventilation and drainage through an $\alpha$-adrenergic agonist vasoconstrictor mechanism. Topical decongestants include phenylephrine, pseudoephedrine, oxymetazoline, and xylometazoline. Common topical decongestant side effects include local irritation and rhinitis medicamentosa (drug-induced rhinitis) with extended use. ${ }^{82}$ As a result, expert guidelines recommend that intranasal decongestant treatment be limited to brief use of less than 10 days ${ }^{10,83}$ with switch to other therapies if symptoms persist after 5 days. ${ }^{84}$

Oral decongestants include phenylephrine and pseudoephedrine, with the latter being more effective. In some patients, their use can be associated with adverse systemic effects, including increased blood pressure, palpitations, appetite loss, and insomnia. ${ }^{13}$

\section{Congestion efficacy in allergic rhinitis}

Both oral and topical decongestants have proven effective for treating nasal congestion associated with allergic rhinitis. Topical decongestants are the most effective treatment for nasal congestion in subjects with allergic rhinitis, but their adverse effect profile make them suitable for short-term use only. ${ }^{6,10,11}$ Selner and colleagues used fiber-optic rhinoscopy to measure nasal patency in patients with nasal congestion due to allergic rhinitis. They reported significant symptomatic relief with both oral pseudoephedrine and topical oxymetazoline, which correlated with the total nasal airway area.$^{85}$

A crossover study of asymptomatic patients with perennial allergic rhinitis due to house dust mite exposure compared the efficacy of the topical decongestant xylometazoline with the antihistamine/oral decongestant combination of cetirizine and pseudoephedrine. Following exposure to allergen and 4 days of treatment, the 2 treatments appeared equally effective in alleviating nasal congestion. ${ }^{86}$ Although the topical decongestant had a more rapid onset of action, its effect was short-lived compared with the extended action of the oral drug combination. ${ }^{86}$ The response over 15 minutes to topical oxymetazoline was compared with the response over 28 days to the intranasal corticosteroid mometasone furoate in another crossover study in patients with perennial allergic rhinitis. The magnitude of the response was significantly greater with oxymetazoline than mometasone furoate for both subjective and objective outcomes of nasal obstruction, although there was high variability of response to oxymetazoline. ${ }^{87}$

A randomized, double-blind, 2-week study in patients with seasonal allergic rhinitis due to ragweed demonstrated that the oral decongestant pseudoephedrine was significantly more effective for relief of nasal congestion than the leukotriene receptor antagonist montelukast ${ }^{88}$ Importantly, the decongestant effect of oral pseudoephedrine in patients with seasonal allergic rhinitis is enhanced when administered in combination with newer $\mathrm{H}_{1}$-antihistamines, including cetirizine ${ }^{89}$ desloratadine, ${ }^{25,90}$ loratadine, ${ }^{24}$ and fexofenadine, ${ }^{26}$ although the improvements in congestion favoring the combination therapy over oral decongestant alone are not consistently significant. Effective congestion relief with oral pseudoephedrine, alone or in combination with an antihistamine, has also been demonstrated in patients with perennial allergic rhinitis (Figure 2). ${ }^{23}$

\section{Congestion efficacy in nonallergic/vasomotor rhinitis}

No studies have been published that evaluated the effects of either oral or topical decongestants versus placebo in patients with nonallergic/vasomotor rhinitis.

\section{Congestion efficacy in rhinosinusitis and/or nasal polyposis}

While decongestants may provide relief from congestion in rhinosinusitis and/or nasal polyposis, no adequately designed studies have evaluated their efficacy in these conditions. ${ }^{7}$ 


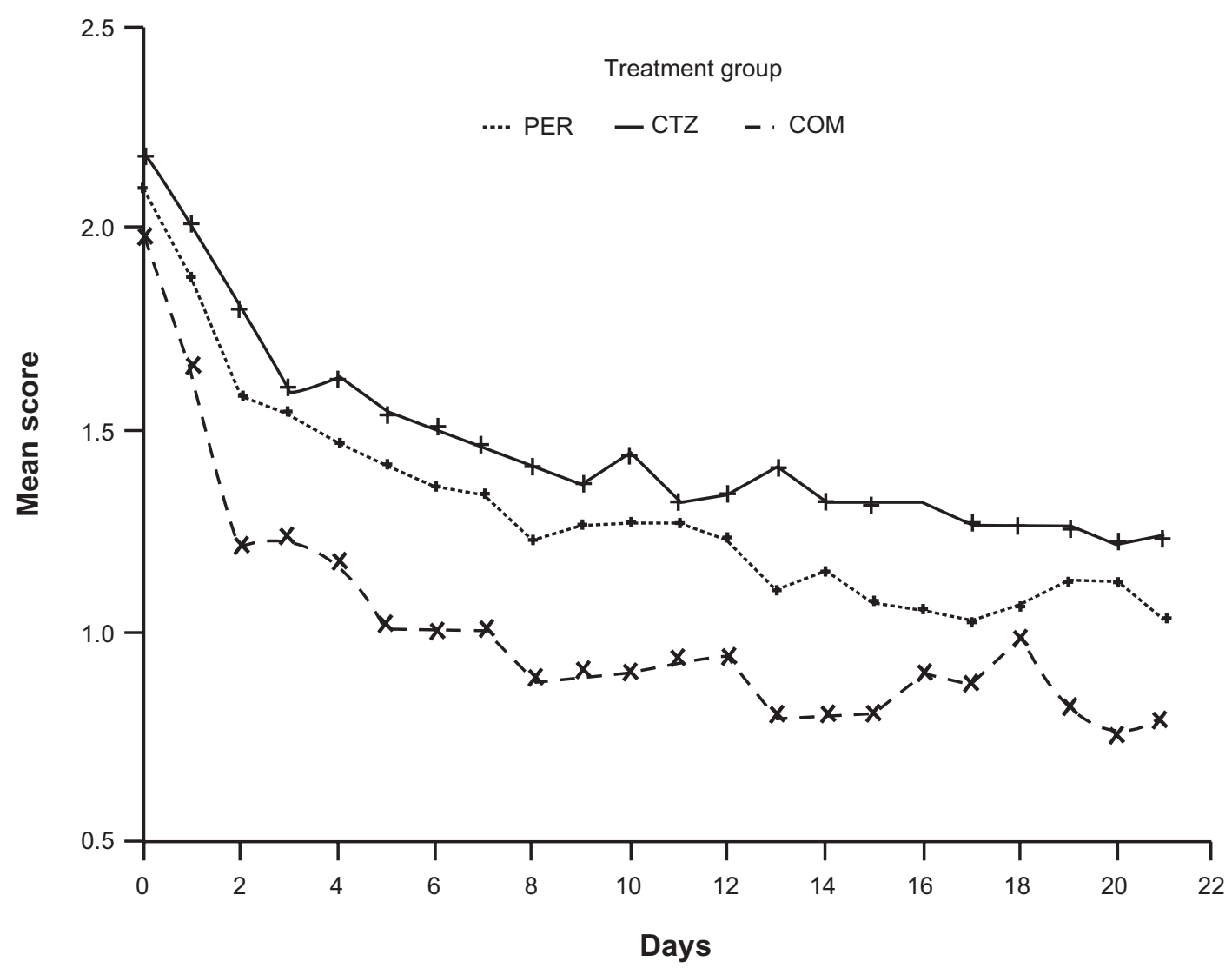

Figure 2 Nasal obstruction mean score versus treatment days. $P<0.00$ I for COM vs CTZ; $P=0.004$ for COM vs PER; $P=0.128$ for $C T Z$ vs $P E R$. Reproduced with permission from Bertrand B, Jamart J, Marchal JL, Arendt C. Cetirizine and pseudoephedrine retard alone and in combination in the treatment of perennial allergic rhinitis: a double-blind multicentre study. Rhinology. 1996;34(2):91-96. ${ }^{23}$ Copyright () 1996 International Rhinologic Society.

Abbreviations: COM, combination of cetirizine and pseudoephedrine; CTZ, cetirizine; PER, pseudoephedrine.

Only a few small studies of decongestants in rhinosinusitis have reported results, and they have failed to demonstrate consistent improvement in congestion. A study comparing topical xylometazoline and oral pseudoephedrine in 10 patients with chronic sinusitis found that the topical agent was more effective for nasal mucosa decongestion, although neither therapy had a significant effect on sinus congestion. ${ }^{91}$ A study of 68 children with acute sinusitis treated with amoxicillin for 14 days found that symptoms improved as quickly in patients receiving a placebo as in those receiving an oral decongestant/antihistamine combination. ${ }^{92}$

\section{Congestion efficacy in the common cold}

A Cochrane database meta-analysis assessed the efficacy of topical decongestants in reducing nasal congestion in adults suffering from the common cold, demonstrating a modest but statistically significant $6 \%$ decrease in patient-reported symptoms after a single dose of intranasal decongestant compared with placebo. ${ }^{93}$ In addition, this meta-analysis also reported a statistically significant, $24 \%$ reduction in nasal airway resistance with the use of a decongestant. ${ }^{93} \mathrm{~A}$ small increase in the risk of insomnia with pseudoephedrine compared with placebo was one of the few adverse events. ${ }^{93} \mathrm{~A}$ double-blind, randomized, placebo-controlled trial in patients suffering from nasal congestion associated with the common cold reported that pseudoephedrine hydrochloride $60 \mathrm{mg} 4$ times daily for 3 days significantly reduced patient-reported congestion compared with placebo on day 1 , but not on day $3 .{ }^{94}$ However, the mean decrease from baseline in congestion/ stuffiness over the study duration was significantly greater with pseudoephedrine than with placebo. ${ }^{94} \mathrm{~A}$ separate singledose trial reported that oxymetazoline reduced nasal airway resistance and symptoms of nasal blockage within 1 hour in adults with the common cold, and the effect persisted for up to 7 hours. ${ }^{95}$

\section{Safety}

The most common side effect of topical decongestants is rhinitis medicamentosa, and it limits the practical utility of these agents to short-term therapy. The most widely used 
oral decongestant, pseudoephedrine, is associated with an increased risk of insomnia, and the US Department of Justice has included pseudoephedrine in the Controlled Substances Act, limiting patients' access. ${ }^{96}$

Despite their proven efficacy against nasal congestion associated with allergic rhinitis, the adverse event profile of topical and oral decongestants limits their usefulness in this disease. In addition, the evidence supporting the utility of decongestants for relief of congestion associated with nonallergic/vasomotor rhinitis, rhinosinusitis, or nasal polyposis is very limited. However, these agents may be a more appropriate option for congestion relief related to the common cold, because of the shorter duration of treatment required.

\section{Intranasal corticosteroids}

Intranasal corticosteroids have potent and broad anti-inflammatory activities and have demonstrated congestion relief across the spectrum of upper respiratory disorders, including seasonal and perennial allergic rhinitis, nasal polyposis, and both acute and chronic rhinosinusitis. ${ }^{6,7,10,11}$ Available intranasal corticosteroids include beclomethasone dipropionate, budesonide, ciclesonide, flunisolide, fluticasone furoate, fluticasone propionate, mometasone furoate, and triamcinolone acetonide. Important features of an intranasal steroid include topical potency with low systemic bioavailability, good acute and long-term efficacy, rapid onset of action, low risk of adverse events, and convenient dosing to promote adherence.

\section{Congestion efficacy in allergic rhinitis}

According to the Allergic Rhinitis and its Impact on Asthma (ARIA) guidelines, corticosteroids are currently the most effective anti-inflammatory medication available for the treatment of rhinitis. ${ }^{6}$ In comparative studies, intranasal corticosteroids have shown superior efficacy compared with other medications used to treat nasal congestion. A metaanalysis of 14 controlled trials in patients with allergic rhinitis showed that intranasal steroids provide superior relief of nasal congestion/blockage compared with oral antihistamines (Figure 3A). ${ }^{27}$ Intranasal steroids also demonstrated greater effectiveness than intranasal $\mathrm{H}_{1}$-antihistamines in improving nasal blockage in a meta-analysis of 4 studies in patients with allergic rhinitis (Figure 3B). ${ }^{28}$ A separate meta-analysis of 4 randomized controlled studies comparing leukotriene receptor antagonists and intranasal steroids in patients with allergic rhinitis showed that steroids were more effective for improving composite nasal symptom scores (individual symptom scores, such as congestion, were not reported). ${ }^{97}$ In addition, several trials have demonstrated superior congestion relief with the intranasal steroid fluticasone propionate versus montelukast in patients with seasonal allergic rhinitis. ${ }^{8,73,74}$

Numerous studies have demonstrated that intranasal steroids effectively relieve congestion due to seasonal allergic rhinitis. A study of 406 adults and children with seasonal allergic rhinitis found that once-daily intranasal budesonide treatment for 4 weeks significantly reduced nasal congestion. ${ }^{98}$ Similarly, once-daily fluticasone propionate administered to adult patients with seasonal allergic rhinitis for 2 weeks also reduced clinician- and patient-rated scores for nasal obstruction. ${ }^{99}$ In a recent pooled analysis of 4 randomized, doubleblind, placebo-controlled studies comprising 982 adult and adolescent patients with seasonal allergic rhinitis, treatment with the intranasal steroid mometasone furoate was significantly more effective than placebo in reducing nasal congestion scores (Figure 4). ${ }^{100}$ Mometasone furoate was effective in relieving congestion across all severities of seasonal allergic rhinitis, with the magnitude of the benefit greatest in patients with the most severe congestion (Figure 4). ${ }^{100}$ A 2-week study of adults with seasonal allergic rhinitis reported that once-daily treatment with triamcinolone acetonide significantly reduced nasal symptoms, including congestion, ${ }^{101}$ and a 2 -week study including adults and adolescents with seasonal allergic rhinitis reported that once-daily treatment with fluticasone furoate significantly reduced nasal symptoms, including congestion. ${ }^{102}$ In a 2-week study of adults and adolescents with seasonal allergic rhinitis, once-daily treatment with ciclesonide significantly reduced total nasal symptoms. However, the individual symptom scores were not reported. ${ }^{103}$

The congestion efficacy of intranasal steroids has been demonstrated across age groups. A study of 249 children with seasonal allergic rhinitis found that fluticasone propionate administered once daily for 4 weeks significantly improved nasal symptoms, including nasal obstruction upon awakening. ${ }^{104}$ In another trial conducted in 679 children with seasonal allergic rhinitis, once-daily mometasone furoate also significantly improved nasal congestion. ${ }^{105}$

In patients with predictable seasonal allergies, intranasal corticosteroids can be used as prophylactic therapy. Graft et al reported that an 8-week course of mometasone furoate $200 \mu \mathrm{g}$ once daily initiated before the start of ragweed season significantly delayed the onset of nasal symptoms, including stuffiness/congestion in patients with seasonal allergic rhinitis. ${ }^{106}$

Intranasal steroids are also effective for treating nasal symptoms of perennial allergic rhinitis. A study of 550 adult and adolescent patients with moderate-to-severe perennial 


\section{A}

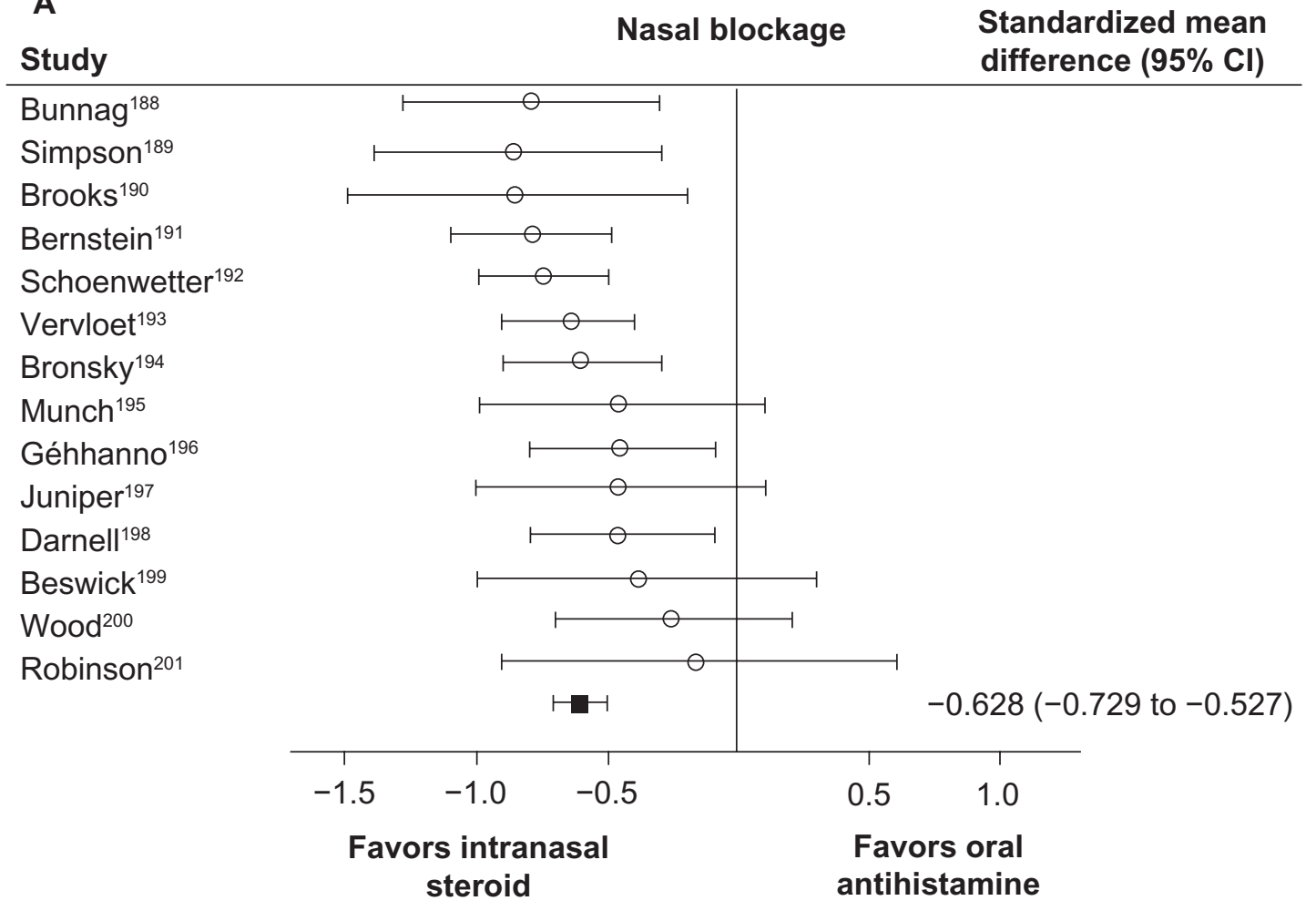

B

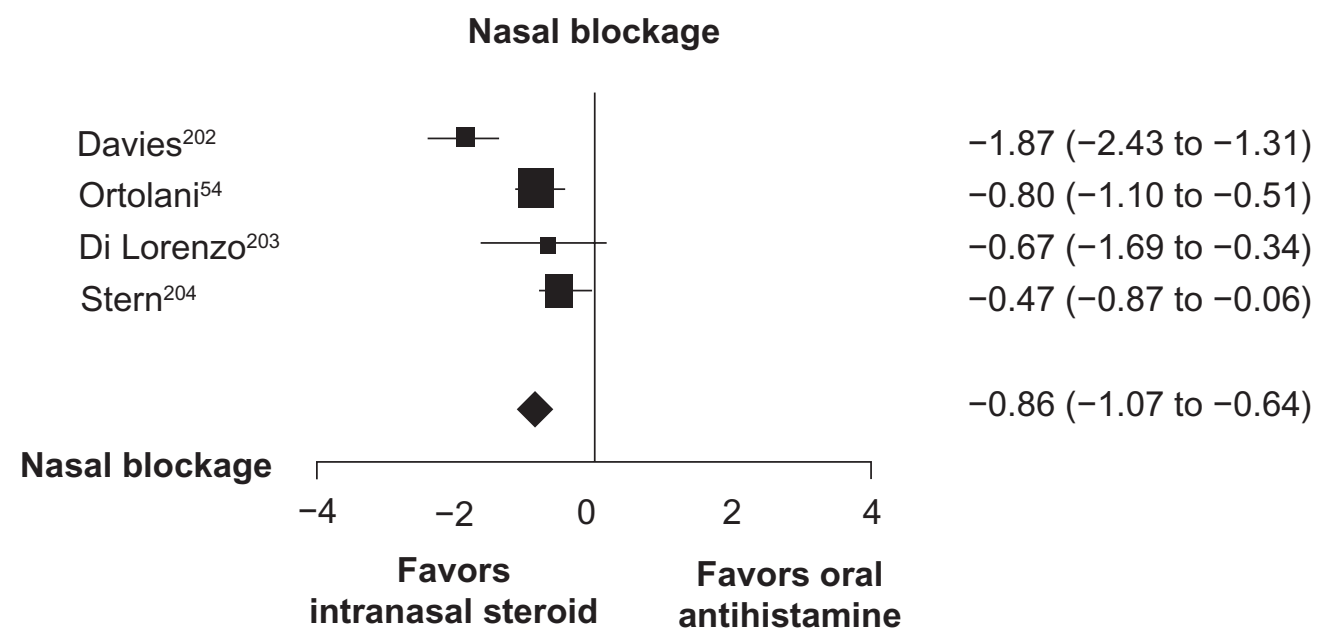

Figure 3 A) Meta-analysis of intranasal corticosteroids versus oral $\mathrm{H}_{1}$-receptor antagonists for the treatment of nasal blockage in allergic rhinitis. Intranasal steroids included beclomethasone dipropionate, fluticasone propionate, triamcinolone acetonide, and budesonide. Oral antihistamines included dexchlorpheniramine, terfenadine, astemizole, loratadine, and cetirizine.Adapted with permission from British Medical Journal,Weiner JM,Abramson MJ, Puy RM, volume 317, I624-I629, Copyright (C) I998 with permission from BMJ Publishing Group Ltd. ${ }^{27}$ B) Meta-analysis of intranasal corticosteroids versus topical $\mathrm{H}_{1}$-receptor antagonists for the treatment of nasal blockage in allergic rhinitis. Intranasal steroids included beclomethasone dipropionate, fluticasone propionate, and budesonide. Topical antihistamines included azelastine and levocabastine. Adapted with permission from Yáñez A, Rodrigo GJ. Intranasal corticosteroids versus topical $\mathrm{H}_{1}$ receptor antagonists for the treatment of allergic rhinitis: a systematic review with metaanalysis. Ann Allergy Asthma Immunol. 2002;89(5):479-484. ${ }^{28}$ Copyright () 2002 American College of Allergy, Asthma and Immunology.

allergic rhinitis found that once-daily treatment with either fluticasone propionate $200 \mu \mathrm{g}$ or mometasone furoate $200 \mu \mathrm{g}$ resulted in a significant reduction in patient-rated nasal congestion compared with placebo. ${ }^{107} \mathrm{~A} 52$-week study of once-daily treatment with ciclesonide in patients with perennial allergic rhinitis demonstrated significant relief of nasal congestion, ${ }^{108}$ but no significant congestion benefit of ciclesonide versus placebo was observed in a 6-week study. ${ }^{109}$

Pediatric patients with perennial allergic rhinitis have also been effectively treated with intranasal steroids. Recently, fluticasone furoate $55 \mu \mathrm{g}$ or $110 \mu \mathrm{g}$ once daily has been reported to reduce total nasal symptom scores in pediatric 


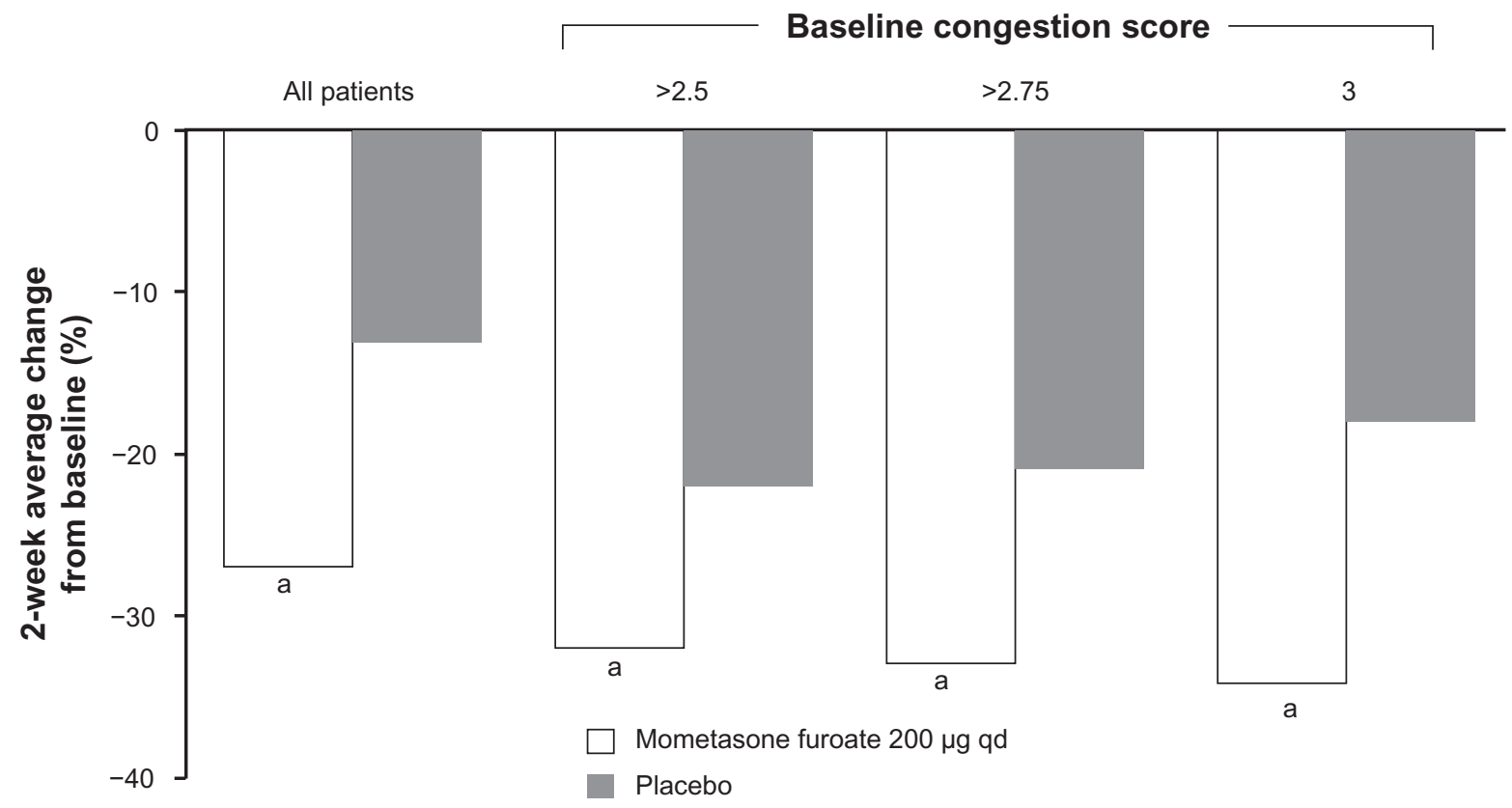

Figure 4 Percent change in congestion symptom score in a pooled analysis of 4 studies with mometasone furoate in seasonal allergic rhinitis. The magnitude of change was greatest in patients with the highest baseline congestion scores. Mean baseline congestion scores in the overall population were 2.24 in the mometasone furoate group and 2.25 in the placebo group. In the $>2.5$ baseline congestion score group, the baseline scores were 2.83 (mometasone furoate) and 2.84 (placebo). In the $>2.75$ group, the baseline scores were 2.94 in both the mometasone furoate and placebo groups. ${ }^{a} P<0.00$ I vs placebo. Adapted with permission from Berger WE, Nayak AS, Staudinger HW. Mometasone furoate improves congestion in patients with moderate-to-severe seasonal allergic rhinitis. Ann Pharmacother. 2005;39(I2):1984-1989.100 Copyright @) 2005 Harvey Whitney Books Co.

patients aged 2 to 11 years with perennial allergic rhinitis, although individual symptom scores were not reported. ${ }^{110}$ In a previous study of 381 children aged 3 to 11 years with perennial allergic rhinitis, mometasone furoate $100 \mu \mathrm{g}$ once daily was also significantly more effective than placebo in reducing patient-rated congestion. ${ }^{111}$

\section{Congestion efficacy in nonallergic/vasomotor rhinitis}

Intranasal corticosteroids have also been evaluated in the treatment of congestion associated with nonallergic rhinitis. Webb et al assessed the efficacy of fluticasone propionate treatment in 983 patients with perennial nonallergic rhinitis, with or without eosinophilia. They found that fluticasone propionate administered for 28 days was significantly better than placebo in improving total nasal symptoms (nasal obstruction, postnasal drip, and rhinorrhea; individual symptom scores were not reported). ${ }^{12}$ A 28-day study including 188 patients with nonallergic rhinitis reported that patient-rated nasal congestion scores were significantly reduced during days 22 to 28 of treatment with fluticasone propionate. ${ }^{113}$

\section{Congestion efficacy in rhinosinusitis}

The anti-inflammatory effect of intranasal steroids has prompted study of these agents in acute and chronic rhinosinusitis. In light of these studies, European guidelines were published as the European Position Paper on Rhinosinusitis and Nasal Polyps (EPOS) recommending the use of intranasal steroids for acute rhinosinusitis as monotherapy or as adjunctive therapy to systemic antibiotics with a high level of evidence (I), while noting that there is no evidence for intranasal steroids in the prophylaxis of recurrent acute rhinosinusitis. ${ }^{7}$ EPOS guidelines also note that there is some evidence for intranasal steroid efficacy in chronic rhinosinusitis without polyps, and that intranasal steroids have a high level of evidence (Ia) against nasal symptoms in chronic rhinosinusitis with polyps. ${ }^{7}$

Several studies have demonstrated the efficacy of intranasal steroids as an adjunct to antibiotics in patients with acute rhinosinusitis. ${ }^{7114-118}$ In 2 studies, patients with acute sinusitis were treated with amoxicillin clavulanate potassium (ACP) for 21 days and randomized to concurrently receive either adjunctive mometasone furoate or placebo. ${ }^{114,116}$ Adjunctive intranasal mometasone furoate therapy was associated with significant improvements in congestion and total symptom scores compared with antibiotic treatment alone. ${ }^{114,116}$ Similar results were found with flunisolide as an adjunct to ACP in patients with acute sinusitis. ${ }^{115}$ The addition of intranasal flunisolide to oral ACP therapy significantly improved congestion/obstruction scores over 3 weeks in these 
patients compared with antibiotic therapy alone (Figure 5). ${ }^{115}$ Furthermore, nasal cytology revealed that neutrophils, eosinophils, and basophils were all significantly decreased in the flunisolide-treated group. ${ }^{115}$ Another study evaluated the combination of fluticasone propionate, cefuroxime, and a topical decongestant in patients with acute sinusitis. In this study, the addition of fluticasone propionate produced significantly higher rates of clinical success (defined as "cured" or "much improved") than the combination of antibiotic/decongestant alone. ${ }^{117}$ The time to clinical success was also significantly shorter with the addition of fluticasone propionate. ${ }^{117}$

Corticosteroid/antibiotic combination therapy has also proved effective in pediatric patients. In 151 children with acute sinusitis, nasal discharge and cough were significantly improved in subjects randomized to treatment with budesonide and amoxicillin compared with amoxicillin alone. ${ }^{18}$ Similarly, significantly higher recovery rates were reported in 52 children with acute maxillary sinusitis who were treated for 10 days with a combination of budesonide plus cefaclor compared with antibiotic therapy plus an oral decongestant. ${ }^{119}$

In addition to being effective when administered as an adjunct to antibiotics, intranasal steroids are also an effective therapy for congestion in acute rhinosinusitis when administered as monotherapy. ${ }^{120}$ In a study reported by Meltzer et al 981 adults and adolescents with acute rhinosinusitis and symptoms persisting beyond 7 days, but without symptoms of severe disease, experienced significantly greater improvements in nasal congestion score during days 2 to 15 of the treatment period with mometasone furoate monotherapy than with amoxicillin alone or with placebo. ${ }^{120}$ A study by Lund and colleagues in patients with chronic rhinosinusitis demonstrated significantly greater improvement in congestion with budesonide than with placebo. ${ }^{121}$

\section{Congestion efficacy in nasal polyposis}

EPOS 2007 guidelines recommend intranasal steroids for the treatment of nasal polyps with a level of evidence of Ia due to their well-documented efficacy in reducing polyp size and relieving symptoms associated with nasal polyposis, including nasal blockage. In 2 small-scale studies, fluticasone propionate nasal spray $200 \mu \mathrm{g}$ twice daily or beclomethasone dipropionate nasal spray $200 \mu \mathrm{g}$ twice daily significantly increased nasal inspiratory flow in patients with nasal polyposis. ${ }^{122,123}$ Two large, randomized, placebo-controlled studies demonstrated that mometasone furoate nasal spray $200 \mu \mathrm{g}$ once daily and particularly $200 \mu \mathrm{g}$ twice daily significantly improved nasal congestion score at 1 month compared with baseline values, and this improvement persisted throughout the 4-month treatment period. ${ }^{124,125}$ In another study, intranasal fluticasone propionate nasal drops $400 \mu \mathrm{g}$ once daily were also significantly more effective than placebo for reducing nasal blockage after 3 months of treatment in patients with bilateral nasal polyposis. ${ }^{126}$ Topical corticosteroids are recommended

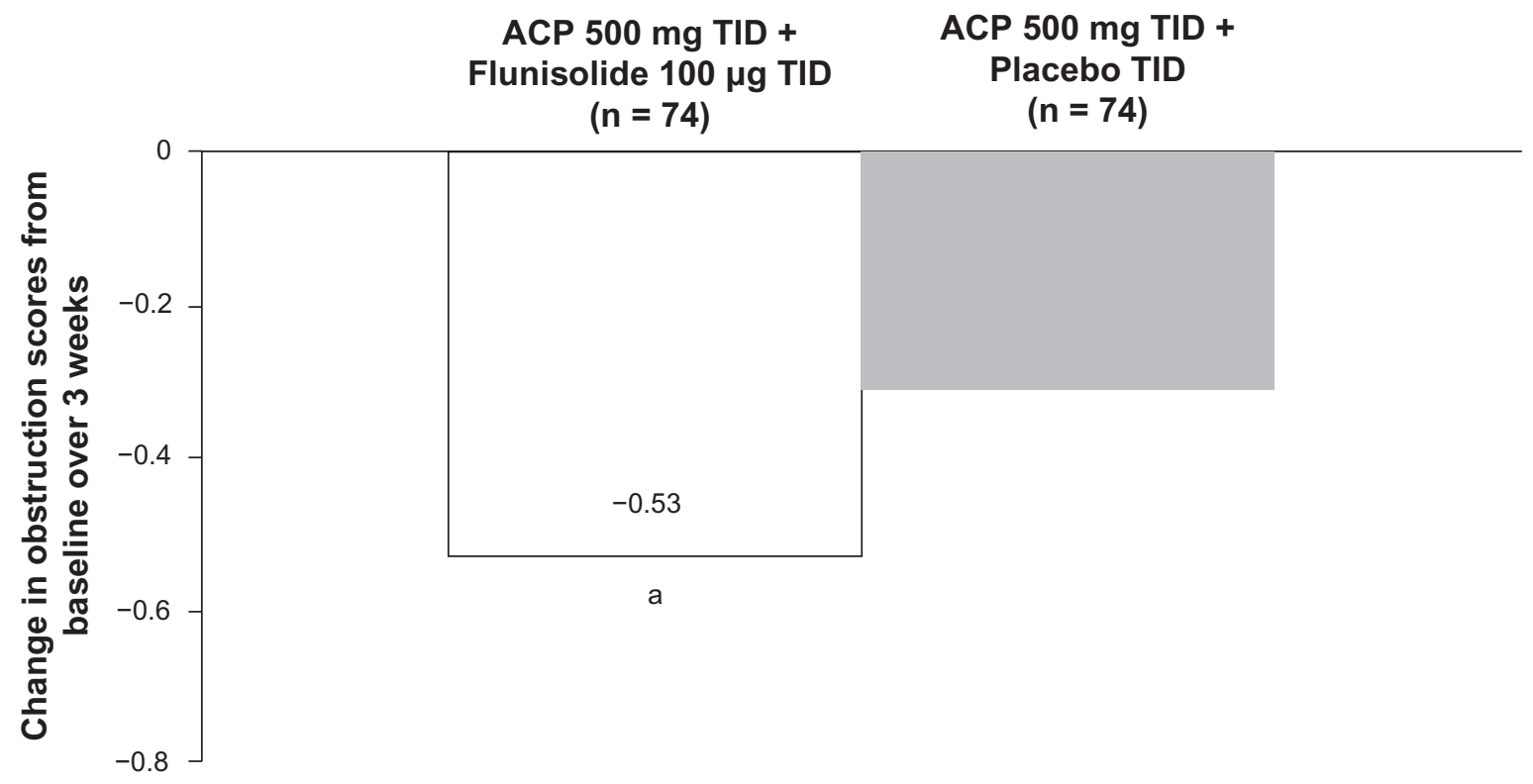

Figure 5 Mean change in turbinate swelling/obstruction score over 3 weeks in patients with acute rhinosinusitis treated with amoxicillin clavulanate potassium (ACP) 500 mg 3 times daily (TID) and either flunisolide $100 \mu \mathrm{g} 3$ times daily or placebo 3 times daily. ${ }^{a} P=0.04$ I versus ACP 500 mg 3 times daily + placebo TID. Reprinted from J Allergy Clin Immunol,Vol 92, Meltzer EO, Orgel HA, Backhaus JW, et al. Intranasal flunisolide spray as an adjunct to oral antibiotic therapy for sinusitis. Pages 8I2-823, Copyright @ I993, with permission from Mosby-Year Book, Inc. ${ }^{115}$ 
in the long-term for all patients with inflammatory polyps unless there is a compelling contraindication. ${ }^{127}$

\section{Congestion efficacy in the common cold}

The evidence for the efficacy of intranasal steroids against congestion associated with the common cold is limited, as only 2 such studies were reported in the literature. One double-blind, randomized, placebo-controlled study in young adults with the common cold reported that high-dose fluticasone propionate $200 \mathrm{mg} 4$ times daily for 6 days significantly reduced nasal congestion on some but not all study days. ${ }^{128}$ Another trial found that intranasal beclomethasone dipropionate $400 \mu \mathrm{g} /$ day failed to reduce symptoms caused by inflammation, such as congestion. ${ }^{129}$

\section{Safety}

Although the efficacy of intranasal corticosteroids is well established, these agents are frequently underused due to concerns about potential systemic adverse effects that are thought to be related to their systemic bioavailability. The systemic bioavailabilities of fluticasone propionate, fluticasone furoate, and mometasone furoate are low to undetectable ( $<1 \%, 0.5 \%$, and $\leq 0.1 \%$, respectively) indicating a low potential for systemic side effects, especially compared with oral steroids and older intranasal agents within the drug class. ${ }^{130-132}$ The systemic bioavailability of other intranasal steroids ranges from roughly $10 \%$ for budesonide ${ }^{133}$ to $44 \%$ for beclomethasone dipropionate. ${ }^{134}$ Triamcinolone acetonide has a mean peak plasma concentration of approximately $0.5 \mathrm{ng} / \mathrm{mL}$ at 1.5 hours postintranasal administration of a single $220 \mu \mathrm{g}$ dose, ${ }^{135}$ and the absolute bioavailability of the inhaled formulation is $25 \%$, which is predominantly due to the swallowed portion. ${ }^{136}$

Differences in the systemic bioavailability of intranasal steroids stem from a number of factors. Low circulating levels of some steroids might be due to minimal absorption across the nasal mucosa of these agents. Bioavailability may also vary with the proportion of drug absorbed by the gastrointestinal tract. However, a significant portion of each intranasal steroid dose is swallowed, so that differences in the extent of first-pass hepatic inactivation seem to account for most of the diversity in systemic bioavailability across agents. ${ }^{137}$

Clinically significant inhibition of the hypothalamicpituitary-adrenal (HPA) axis is a potentially serious consequence of systemic exposure to corticosteroids. Using cortisol concentrations as an indicator of HPA activity, mometasone furoate was found to have no effect on cortisol secretion in adults, even when the drug was administered at 20 times the recommended dose. ${ }^{138}$ Additionally, a study of children aged 3 to 12 years who were treated with intranasal mometasone furoate for up to 14 days found no significant effect on mean plasma cortisol concentrations. ${ }^{139}$ Intranasal triamcinolone acetonide was also found to have no statistically significant effect on urine cortisol/creatine ratios in a study of 59 children with a mean age of 7.2 years. ${ }^{140}$ Although this same study reported small but detectable differences in plasma cortisol levels with fluticasone propionate, ${ }^{140}$ additional studies have demonstrated no detectable effects on the HPA axis following short-term intranasal triamcinolone acetonide or fluticasone propionate at their recommended dosages. ${ }^{141}$ Several studies with fluticasone furoate have reported small, variable changes in cortisol levels compared with placebo, which taken in whole cannot eliminate a potential effect of fluticasone furoate on adrenal function, especially in pediatric patients. ${ }^{132}$ To minimize the potential risk of systemic side effects of any intranasal steroid, each patient's dose should be titrated to the lowest dose that effectively controls symptoms.

Systemic corticosteroid exposure can cause a reduction in growth velocity in pediatric patients, even in the absence of detectable effects on HPA-axis function. ${ }^{142}$ A study of 100 prepubescent children aged 6 to 9 years found that 1 year of intranasal beclomethasone dipropionate treatment resulted in detectable growth suppression. ${ }^{142}$ The mean change in standing height at study end point was $5.0 \mathrm{~cm}$ and $5.9 \mathrm{~cm}$ in beclomethasone- and placebo-treated children, respectively. ${ }^{142}$ However, a 1-year growth study of 108 prepubescent children aged 3 to 9 years reported no statistically significant difference in growth velocity in patients receiving intranasal fluticasone propionate compared with placebo, and no evidence of clinically relevant changes in HPA-axis function or bone mineral density. ${ }^{130}$ Additionally, neither intranasal triamcinolone acetonide nor fluticasone propionate were found to have significant effects on short-term lower-leg growth velocity in a 2-week study. ${ }^{140} \mathrm{~A}$ long-term study noted no suppressive effect on growth over 1 year in 98 children aged 3 to 9 years treated with mometasone furoate. ${ }^{143}$

There are concerns that long-term corticosteroid use might result in atrophic changes in the nasal mucosa. However, no evidence of adverse changes in the nasal mucosa, including atrophy or epithelial thickness, were noted after 12 months of daily treatment with mometasone furoate $200 \mu \mathrm{g} .{ }^{144}$ Similarly, treatment with intranasal triamcinolone acetonide $220 \mu \mathrm{g}$ daily for 6 months did not cause atrophy of the nasal mucosa or impairment of mucociliary function in patients with perennial allergic rhinitis. ${ }^{145}$ 
Despite the fact that intranasal steroids are the most effective therapy for symptoms associated with allergic rhinitis, they tend to be underused, especially in pediatric patients, due to concerns over potential side effects. However, the low to negligible systemic bioavailabilities of newer intranasal steroids, in conjunction with the abundance of clinical trial evidence, suggest that these concerns may be somewhat exaggerated. Based on clinical trials that enrolled adult, adolescent, and pediatric patients with allergic rhinitis, the incidence of adverse events associated with the use of currently marketed intranasal corticosteroids was generally low and similar to placebo. ${ }^{130-135}$ Numerous studies have demonstrated that intranasal corticosteroids offer effective relief of nasal congestion in seasonal allergic rhinitis and perennial allergic rhinitis, and can even be used to prevent nasal congestion associated with seasonal allergic rhinitis when given before the start of allergen season. Intranasal corticosteroids have also provided relief of congestion associated with nonallergic rhinitis and have demonstrated superior efficacy with respect to congestion relief in patients with acute rhinosinusitis, both when used as an adjunct to antibiotics and as monotherapy. In addition, intranasal corticosteroids provide effective congestion relief in patients with nasal polyposis. Further evaluation of their ability to relieve congestion associated with the common cold is needed.

Although intranasal steroids are the most effective agents for the relief of congestion associated with allergic rhinitis, there is room for improvement in this treatment class. Mean nasal congestion scores are not reduced to normal levels in clinical trials with these agents, and congestion is not effectively reduced in all patients. Systemic availability is very low for some intranasal steroids, but for others it can be quite substantial, leading to safety concerns.

\section{Other pharmacotherapies}

Cromolyn prevents inflammation through its inhibition of mast cells, macrophages, eosinophils, monocytes, and platelets. ${ }^{146}$ While cromolyn is an effective treatment for symptoms of sneezing, rhinorrhea, and nasal itching in patients with allergic rhinitis, it is less efficacious against nasal obstruction. ${ }^{6}$ In addition, its decongestant effect is inferior to that of intranasal steroids, such as mometasone furoate. ${ }^{55}$ Cromolyn has a good safety record and is available without prescription. ${ }^{147}$ Intranasal cromolyn sodium has not been proven effective for treatment of congestion associated with other upper respiratory diseases, including nonallergic/vasomotor rhinitis and the common cold, as well as rhinosinusitis and/or nasal polyposis. ${ }^{?}$
A topical form of aspirin, lysine-aspirin, has been used in the treatment of nasal polyposis. Objective assessments showed that lysine-aspirin had significant clinical benefit in improving nasal blockage and reducing polyp size when used in addition to topical corticosteroids, ${ }^{148}$ possibly related to a reduction in leukotriene receptors. ${ }^{16}$

Because parasympathetic nervous system activation induces watery secretion and vasodilatation, it has been postulated that topical anticholinergics may provide efficacy against nasal congestion. However, randomized, controlled trials have shown that the anticholinergic ipratropium bromide provides no relief of nasal obstruction in patients with perennial allergic and nonallergic/vasomotor rhinitis. ${ }^{6,149,150}$ In addition, the systemic bioavailability of intranasal ipratropium $(7 \% \text { to } 18 \%)^{151}$ is much higher than that of the secondgeneration intranasal corticosteroids, including fluticasone propionate, mometasone furoate and fluticasone furoate, and thus increases the potential for systemic side effects. As patients with perennial rhinitis typically suffer from a variety of symptoms, including nasal congestion, itching, and sneezing, other therapeutic agents are preferable as first-line treatment in the majority of patients with allergic rhinitis. ${ }^{6}$

Oral methylprednisolone has been shown to provide significant relief of nasal congestion in patients with moderateto-severe seasonal allergic rhinitis symptoms compared with placebo over a 1-week treatment period. ${ }^{152}$ In addition, it has demonstrated the ability to relieve a nonvascular component of allergic congestion that is unaffected by decongestant therapy. ${ }^{153}$ However, systemic steroids should not be used as first-line treatment for allergic rhinitis, but only as a therapy of last resort when other therapeutic options have been exhausted. ${ }^{6}$ Oral corticosteroids have also been evaluated in acute rhinosinusitis, but there is little evidence to support their use for purposes other than pain relief. ${ }^{84}$ Although no data is available for their efficacy in chronic rhinosinusitis without nasal polyps, recent studies show that short courses of oral corticosteroids reduce polyps and improve congestion in most patients with chronic rhinosinusitis and polyps., ${ }^{754}$ From a safety perspective, for nasal congestion, systemic corticosteroids should be limited to short-term use due to their side-effect profile, ${ }^{6}$ which effectively reduces the clinical usefulness of these agents. In addition, systemic steroids should be limited as much as possible in children, and avoided in pregnant women and in patients with a known contraindication. ${ }^{6}$

The $\mathrm{C}$-fiber stimulant capsaicin has also been tested as a therapeutic option for relief of nasal congestion. It has been suggested that the therapeutic effect of capsaicin could be 
mediated by $\mathrm{C}$-fiber desensitization through continuous stimulation. A study in adult patients with severe, chronic nonallergic rhinitis receiving intranasal capsaicin under local anesthesia once weekly for 5 weeks reported a significant improvement in nasal obstruction throughout a 6-month follow-up period. ${ }^{155}$ However, in a separate randomized, double-blind, placebo-controlled trial in adults with nonallergic rhinitis, capsaicin provided no relief of nasal congestion. ${ }^{17}$

Menthol is an alcohol that has been widely used for the relief of nasal symptoms in various upper respiratory diseases. A double-blind, randomized trial in patients with nasal obstruction due to the common cold found that oral administration of a lozenge containing $11 \mathrm{mg}$ of menthol increased patient's sensation of airflow 10 minutes after lozenge administration, but this effect did not persist. ${ }^{156}$ Additionally, menthol did not have an impact on nasal resistance to airflow. ${ }^{156}$

There is mounting evidence that nasal irrigation with saline is beneficial in treating nasal symptoms in acute and chronic rhinosinusitis, when used as a sole modality or as adjunctive therapy, although such treatment is less effective than intranasal corticosteroids. ${ }^{7,83,157,158}$ Various mechanisms, including improved mucous clearance, may account for the improvement. ${ }^{157}$ Recent controlled trials in both children and adults with rhinosinusitis and allergy show that saline washouts significantly relieved nasal congestion and other symptoms as well as improved sleep and quality of life. ${ }^{159,160}$

\section{Immunotherapy}

Immunotherapy for allergic rhinitis involves periodic exposure, usually weekly by subcutaneous injection (SCIT) or daily by sublingual tablet or drops (SLIT), to incrementally larger doses of allergen(s). ${ }^{20,161-163} \mathrm{~A}$ maintenance dose is usually continued long-term with SCIT at intervals of 2 to 6 weeks, ${ }^{20}$ and allergen(s) may be modified with adjuvant agents to enhance allergen immunogenicity. ${ }^{20,161}$ Immunotherapy offers a number of advantages over conventional pharmacotherapy, as it appears to offer some benefit in cases of severe allergic rhinitis, ${ }^{20}$ and its clinical efficacy can be maintained for years after treatment discontinuation. ${ }^{161}$ In addition, immunotherapy may reduce the risk of developing asthma in patients with allergic rhinitis ${ }^{161}$ and may prevent new sensitizations. ${ }^{161}$ A study by Durham et al evaluated the long-term efficacy of grass pollen SCIT in patients who responded favorably to treatment for up to 4 years. After discontinuation of therapy for 3 years, symptom scores and rescue medication scores remained at low levels and were similar to those of patients who continued immunotherapy. ${ }^{164}$
SCIT has been shown to effectively reduce nasal congestion in allergic patients. A double-blind, placebo-controlled trial in patients allergic to Parietaria found that treatment with an alum adsorbed partially purified Parietaria extract (Alpare parietaria) for 2 years significantly decreased nasal blockage in the actively treated immunotherapy group compared with placebo. ${ }^{165}$ Similarly, a randomized, double-blind, placebocontrolled study in adults with a history of severe grass pollen allergy not controlled by standard antiallergic drugs found that administration of a depot grass pollen extract (timothy grass, Phleum pratense) significantly reduced blocked nose during the pollen season compared with placebo. ${ }^{166}$

Similar to SCIT, SLIT has also demonstrated congestion relief in subjects with allergic rhinitis. An older study investigating the utility of oral ragweed immunotherapy reported that nasal symptom scores during the natural allergen season were numerically but not statistically lower in the SLIT group versus the placebo group. ${ }^{167}$ However, a more recent double-blind, placebo-controlled study of 634 patients with allergies to timothy grass pollen demonstrated that sublingual timothy grass tablet significantly improved all ocular and nasal symptom scores, including blocked nose. ${ }^{168}$ Timothy grass tablet SLIT has also proven effective when initiated prior to the allergy season and continued throughout the pollen season. ${ }^{162,169}$ A recent multinational, randomized, double-blind, placebo-controlled study performed in 628 grass pollen-allergic patients reported that treatment with a SLIT tablet containing a mixture of equal proportions of 5 grass pollens (including orchard grass, meadow grass, perennial ryegrass, sweet vernal, and timothy) initiated 4 months before the pollen season and continued throughout the season significantly reduced nasal congestion scores compared with placebo. ${ }^{170}$ In addition to the efficacy of grass tablet SLIT on nasal congestion in patients with seasonal grass allergies, house dust mite SLIT has also been shown to reduce nasal blockage in patients with perennial allergic rhinitis. Patients with perennial rhinitis related to house dust mite sensitization randomized to receive house dust mite SLIT for 2 years reported significant improvements in congestion scores versus placebo after 1 year, and these improvements persisted at the end of the second year. ${ }^{171}$

Potentially fatal anaphylaxis is the most serious clinical concern surrounding the use of allergen immunotherapy. ${ }^{161}$ Cases of fatal anaphylactic reactions have been reported with the use of SCIT, ${ }^{20}$ but not with SLIT tablets. The proportion of patients receiving SCIT who suffer systemic reactions is estimated at $5 \%$ to $10 \% .{ }^{20}$ With SLIT tablets, the most common adverse events include swelling and itching of the ears, 
mouth, and throat, which are typically mild in severity and resolve spontaneously after a short period of time. ${ }^{164,168,169}$ Because of the potential for fatal or near-fatal anaphylactic reaction to immunotherapy, SCIT is always administered in a physician's office with ready availability of epinephrine for rescue, whereas SLIT tablets have been designated to be given under a physician's supervision on the first 1 or 2 occasions, but can be taken by the patient on their own at home thereafter.

Immunotherapy is specifically designed to treat both seasonal and perennial allergic rhinitis and has demonstrated efficacy against nasal congestion in both conditions. However, concerns related to SCIT, including potential for anaphylaxis, uncertainty concerning the strength of administered extracts, the discomfort and expense of frequent injections with SCIT, and patient inconvenience, have limited its adoption in clinical practice. ${ }^{20}$ Despite these problems, immunotherapy may be indicated for patients with allergic rhinitis if the relief achieved with pharmacotherapy is inadequate or to reduce disease progression, as immunotherapy is the only intervention that alters the natural history of allergic disease. ${ }^{20}$ In addition, the recent introduction of fixed-dose tablet SLIT may offer an effective and potentially safer and more convenient alternative to SCIT.

\section{Surgical treatments}

Surgical treatment for nasal congestion should be reserved for severe or persistent cases of nasal obstruction. The relevant anatomical sites for surgical intervention include the nasal septum, nasal valve, inferior and middle turbinates, and nasopharynx. The nasal septum can interfere with nasal airflow when it is skewed from its midline position, either unilaterally or bilaterally. Deformity of the septum can be due to curvatures of anterior cartilages, spurring or displacement of bony nasal supports, or both. Among available surgical procedures for improving nasal obstruction caused by septal deformity are septoplasty and submucous resection of the septum.

The long-term benefits of septal surgery have been described in a number of studies. ${ }^{172-174} \mathrm{~A}$ trial in patients diagnosed with a septal deviation requiring surgery to eliminate obstruction reported a statistically significant increase in volume as measured by acoustic rhinometry and a decrease in symptomatic congestion. ${ }^{172}$ In addition, a 2- to 3-year follow-up study of patients who underwent septoplasty found significant improvement in nasal breathing and congestion. ${ }^{173}$ A retrospective study found a high degree of patient satisfaction in those who had undergone septoplasty for nasal obstruction 3 months earlier. ${ }^{174}$
Anatomical regions of the nasal airway that dynamically affect nasal breathing include the external nasal valve and the internal nasal valve. The nasal valve is the narrowest portion of the nasal airway and accounts for $50 \%$ of normal nasal resistance. Collapse of the nasal valve with inspiration (alar collapse) is a common cause of nasal obstruction. Surgical repair of this area can improve nasal airflow and decrease obstruction/ congestion. ${ }^{175}$

The nasal turbinates are paired bilateral structures arising from the ethmoid and maxillary bones. Turbinate hypertrophy can include bony structures with or without mucosal swelling, which can be differentiated by acoustic rhinometry pre- and postnasal decongestion. Surgery should be reserved for correcting bony structural problems or mucosal swelling that has failed to remit with maximal medical therapy, including use of oral corticosteroids. Various procedures have been used to reduce turbinate bulk, including turbinectomy (resection and surgical reduction of the turbinates), submucous resection of turbinate bone, submucosal diathermy, laser ablation, and radiofrequency ablation. ${ }^{176,177}$

A number of positive outcomes have been reported in patients who have undergone turbinate surgery. The procedure has been reported to improve nasal airflow, ${ }^{177,178}$ reduce symptoms of nasal obstruction, ${ }^{177,179,180}$ and increase nasal cavity volume. ${ }^{180}$ Although turbinate surgery is effective in properly selected patients, the procedure is subject to a number of drawbacks, including persistent nasal problems as the result of less aggressive procedures. On the other hand, complications of overly aggressive or complete turbinectomies include the risk of atrophic rhinitis and "open nose." 181 In addition, postoperative development of dry rhinitis characterized by the accumulation of stagnant secretions resulting from excessive removal of the inferior turbinate has also been reported. ${ }^{181}$

Adenoid hypertrophy can affect nasal airflow by causing posterior nasal/nasopharyngeal obstruction. In many patients, especially children, adenoid hypertrophy is associated with hypertrophy of the inferior turbinates, ${ }^{182}$ suggesting that adenoidectomy might improve symptoms of nasal obstruction in these patients. While adenoidectomy has been shown to decrease nasal congestion and improve nasal airflow in children, ${ }^{182,183}$ its role in adults is limited.

A major symptom of chronic rhinosinusitis is nasal congestion, and endoscopic sinus surgery (ESS) has been performed in such cases as a means of relieving congestion. The benefits of ESS in patients with chronic rhinosinusitis have been demonstrated in a number of studies. ESS produced significant improvements in symptoms including congestion and nasal obstruction, ${ }^{184,185}$ and in quality-of-life measures. ${ }^{186}$ 
Patients who underwent ESS for chronic sinusitis also had significantly improved nasal endoscopy scores. ${ }^{186}$ Based on comparisons of pre- and postoperative rhinometry and rhinomanometry, ESS produces an increase in nasal cavity volumes and a decrease in nasal inspiratory resistance. ${ }^{185,187}$

Surgery remains an important treatment option for congestion, particularly in subjects with inadequate response to prior therapeutic modalities or those with structural abnormalities. The potential benefits of surgical approaches should be weighed against the risk for complications.

\section{Treatment of less common specific rhinopathies}

In addition to the common rhinopathies of allergic rhinitis and acute and chronic sinusitis, there are a number of specific nasal conditions that are associated with symptoms of nasal congestion. Several of these are listed in the Table 1, along with recommendations for their treatment.

\section{Summary}

Congestion is a cardinal symptom of upper respiratory diseases and is often a focus of treatment. In all cases, a stepwise approach is recommended for the management and treatment of congestion, consisting of (1) diagnosis of the cause(s), (2) patient education and monitoring, (3) avoidance of environmental trigger factors where possible, (4) pharmacotherapy, and (5) allergen immunotherapy (only in patients with allergic rhinitis) or surgery for patients in whom the condition cannot be controlled with the previous measures.

A variety of pharmacologic therapies are available for the treatment of nasal congestion in various upper respiratory diseases, such as allergic rhinitis, nonallergic/vasomotor rhinitis, rhinosinusitis, nasal polyposis, and the common cold. The most extensively evaluated therapies for congestion include antihistamines, decongestants, leukotriene receptor antagonists, and intranasal corticosteroids. Intranasal steroids are currently the most effective medication available for the treatment of congestion associated with allergic rhinitis and have also demonstrated effective congestion relief in other upper respiratory diseases. It is important to note that while intranasal steroids have proven to be more effective than other classes of agents for the relief of congestion in controlled clinical trials, they do not reduce mean nasal congestion scores to normal levels, nor do they effectively reduce congestion in every patient. Thus, the efficacy of a particular therapeutic selection should be evaluated for each patient, with clinical trial results and comparison studies informing therapy considerations and helping to establish expectations.

Immunotherapy has emerged as an effective option for those patients with allergic rhinitis in whom pharmacotherapy is insufficient, while surgery may be warranted in cases of severe refractory congestion or in patients with structural abnormalities. Treatment of less common rhinopathies should be tailored to the individual diagnosis and the needs of the particular patient.

\section{Acknowledgments}

Editorial assistance was provided by Henry Hamilton, $\mathrm{PhD}$, former employee of Health Science Communications, Inc., and Joyce O'Connor, MS of Health Science Communications, Inc. This assistance was funded by Schering-Plough Corporation, now Merck \& Co., Whitehouse Station, NJ, USA.

\section{Disclosures}

Dr Meltzer: grant/research support from Alcon, Amgen, Apotex, AstraZeneca, Boehringer Ingelheim, Capnia, Genentech, GlaxoSmithKline, MAP Pharmaceuticals, Meda, Merck, Novartis, Pharmaxis, sanofi-aventis, Schering-Plough

Table I Treatment of some less common rhinopathies

\begin{tabular}{|c|c|}
\hline Condition & Recommendation \\
\hline Occupational rhinitis & Identify and avoid the irritant or allergen \\
\hline \multirow[t]{3}{*}{ Nasal polyps } & Assess for underlying infection, aspirin sensitivity, fungal or bacterial \\
\hline & hypersensitivity, cystic fibrosis, vasculitis, or other complicating disease \\
\hline & $\begin{array}{l}\text { Consider therapy with intranasal corticosteroids, antileukotrienes, } \\
\text { antibiotics, topical aspirin, surgery }\end{array}$ \\
\hline Rhinitis medicamentosa & $\begin{array}{l}\text { Treat with intranasal or oral corticosteroids. Wean off intranasal } \\
\text { decongestants }\end{array}$ \\
\hline $\begin{array}{l}\text { Aspirin-exacerbated respiratory disease (aspirin intolerance), } \\
\text { including aspirin-induced rhinosinusitis and/or asthma }\end{array}$ & $\begin{array}{l}\text { Avoid aspirin and other nonsteroidal anti-inflammatory drugs. Consider } \\
\text { topical aspirin or oral aspirin desensitization }\end{array}$ \\
\hline Nasal congestion during pregnancy & Consider Breathe Right ${ }^{\circledR}$ nasal strips at night instead of medications \\
\hline Nasal septal deviation & If obstruction is severe and persistent, consider surgical consultation \\
\hline
\end{tabular}


Corporation, now Merck \& Co., Whitehouse Station, NJ, USA, Sepracor, Skye Pharma, Teva, Vocel, Wyeth; has been a consultant/speaker for Abbott, Alcon, Amgen, AstraZeneca, Capnia, Dey, Evolutec, Genentech, GlaxoSmithKline, Greer, Inspire, Johnson and Johnson, MAP Pharmaceuticals, Meda, Merck, Novartis, Pfizer, sanofi-aventis, Schering-Plough Corporation, now Merck \& Co., Whitehouse Station, NJ, USA, Sepracor, Shionogi, VentiRx, Wyeth.

Dr Caballero: clinical research for GlaxoSmithKline, Schering-Plough Corporation, now Merck \& Co., Whitehouse Station, NJ, USA, MSD and has received honoraria from them for lectures.

Dr Fromer: none.

Dr Krouse: consultant to Schering-Plough Corporation, now Merck \& Co., Whitehouse Station, NJ, USA and Alcon Labs.

Dr Scadding: consultant/advisory board member for ALK, Britannia Pharmaceuticals, CMP Therapeutics, Groupo Uriach, GSK, Merck, sanofi-aventis, ScheringPlough Corporation, now Merck \& Co., Whitehouse Station, NJ, USA, UCB; has received research funds from ALK, GSK, UCB, Schering-Plough Corporation, now Merck \& Co., Whitehouse Station, NJ, USA; has given talks for ALK, GSK, Merck, Schering-Plough Corporation, now Merck \& Co., Whitehouse Station, NJ, USA, UCB and has co-written articles for Schering-Plough Corporation, now Merck \& Co., Whitehouse Station, NJ, USA and GSK.

\section{References}

1. Prenner BM, Schenkel E. Allergic rhinitis: treatment based on patient profiles. Am J Med. 2006;119(3):230-237.

2. Shedden A. Impact of nasal congestion on quality of life and work productivity in allergic rhinitis: findings from a large online survey. Treat Respir Med. 2005;4(6):439-446.

3. Lundbäck B. Epidemiology of rhinitis and asthma. Clin Exp Allergy. 1998;28 Suppl 2:3-10.

4. Hickner JM, Bartlett JG, Besser RE. Principles of appropriate antibiotic use for acute rhinosinusitis in adults: background. Ann Intern Med. 2001;134(6):498-505.

5. Leggett JE. Acute sinusitis. When - and when not - to prescribe antibiotics. Postgrad Med. 2004;115(1):13-19.

6. Bousquet J, Van Cauwenberge P, Khaltaev N. Allergic rhinitis and its impact on asthma. J Allergy Clin Immunol. 2001;108(5 Suppl): S147-S334.

7. Fokkens W, Lund V, Mullol J. European position paper on rhinosinusitis and nasal polyps. Rhinol Suppl. 2007;(Suppl 20):1-136.

8. Ratner PH, Howland WC III, Arastu R, et al. Fluticasone propionate aqueous nasal spray provided significantly greater improvement in daytime and nighttime nasal symptoms of seasonal allergic rhinitis compared with montelukast. Ann Allergy Asthma Immunol. 2003;90(5):536-542.

9. American Academy of Allergy, Asthma and Immunology. Available from: http://www.aaaai.org/members/cme_ce/allergicdisorders/case1. stm. Accessed August 6, 2009.

10. van Cauwenberge P, Bachert C, Passalacqua G, et al. Consensus statement on the treatment of allergic rhinitis. European Academy of Allergology and Clinical Immunology. Allergy. 2000;55(2):116-134.
11. Managing the patient with allergic rhinitis. In: The Allergy Report. Milwaukee, WI: The American Academy of Allergy, Asthma and Immunology; 2000.

12. Canonica GW, Holgate ST, Karlsson G, et al. The impact of allergic rhinitis on quality of life and other airway diseases. Summary of a European conference. Allergy. 1998;53(41 Suppl):1-31.

13. Dykewicz MS, Fineman S, Skoner DP, et al. Diagnosis and management of rhinitis: complete guidelines of the Joint Task Force on Practice Parameters in Allergy, Asthma and Immunology. American Academy of Allergy, Asthma, and Immunology. Ann Allergy Asthma Immunol. 1998;81(5 Pt 2):478-518.

14. Skoner DP. Treating allergic rhinitis: current challenges and future approaches. Available from: http://www.aaaai.org/members/cme_ce/ allergicdisorders/case1.stm. Accessed August 6, 2009.

15. 2005 Gallup Study of Allergies (Phase II Report). A service of Multisponsor Surveys, Inc. under a license agreement with The Gallup Organization.

16. Parikh AA, Scadding GK. Intranasal lysine-aspirin in aspirin-sensitive nasal polyposis: a controlled trial. Laryngoscope. 2005;115(8): $1385-1390$.

17. Blom HM, Van Rijswijk JB, Garrelds IM, Mulder PG, Timmermans T, Gerth van Wijk R. Intranasal capsaicin is efficacious in non-allergic, non-infectious perennial rhinitis. A placebo-controlled study. Clin Exp Allergy. 1997;27(7):796-801.

18. Gerth Van Wijk R, Terreehorst IT, Mulder PG, Garrelds IM, Blom HM, Popering S. Intranasal capsaicin is lacking therapeutic effect in perennial allergic rhinitis to house dust mite. A placebo-controlled study. Clin Exp Allergy. 2000;30(12):1792-1798.

19. Eccles R. Menthol: effects on nasal sensation of airflow and the drive to breathe. Curr Allergy Asthma Rep. 2003;3(3):210-214.

20. Plaut M, Valentine MD. Clinical practice. Allergic rhinitis. $N$ Engl $J$ Med. 2005;353(18):1934-1944.

21. Patanase [package insert]. Fort Worth, TX: Alcon Laboratories, Inc; 2008.

22. Hore I, Georgalas C, Scadding G. Oral antihistamines for the symptom of nasal obstruction in persistent allergic rhinitis - a systematic review of randomized controlled trials. Clin Exp Allergy. 2005;35(2):207-212.

23. Bertrand B, Jamart J, Marchal JL, Arendt C. Cetirizine and pseudoephedrine retard alone and in combination in the treatment of perennial allergic rhinitis: a double-blind multicentre study. Rhinology. 1996;34(2):91-96.

24. Bronsky E, Boggs P, Findlay S, et al. Comparative efficacy and safety of a once-daily loratadine-pseudoephedrine combination versus its components alone and placebo in the management of seasonal allergic rhinitis. J Allergy Clin Immunol. 1995;96(2):139-147.

25. Pleskow W, Grubbe R, Weiss S, Lutsky B. Efficacy and safety of an extended-release formulation of desloratadine and pseudoephedrine vs the individual components in the treatment of seasonal allergic rhinitis. Ann Allergy Asthma Immunol. 2005;94(3):348-354.

26. Sussman GL, Mason J, Compton D, Stewart J, Ricard N. The efficacy and safety of fexofenadine $\mathrm{HCl}$ and pseudoephedrine, alone and in combination, in seasonal allergic rhinitis. J Allergy Clin Immunol. 1999;104(1):100-106.

27. Weiner JM, Abramson MJ, Puy RM. Intranasal corticosteroids versus oral $\mathrm{H} 1$ receptor antagonists in allergic rhinitis: systematic review of randomised controlled trials. BMJ. 1998;317(7173):1624-1629.

28. Yáñez A, Rodrigo GJ. Intranasal corticosteroids versus topical $\mathrm{H}_{1}$ receptor antagonists for the treatment of allergic rhinitis: a systematic review with meta-analysis. Ann Allergy Asthma Immunol. 2002;89(5): 479-484.

29. Banov CH, Lieberman P; Vasomotor Rhinitis Study Groups. Efficacy of azelastine nasal spray in the treatment of vasomotor (perennial nonallergic) rhinitis. Ann Allergy Asthma Immunol. 2001;86(1):28-35.

30. Purello-D'Ambrosio F, Isola S, Ricciardi L, Gangemi S, Barresi L, Bagnato GF. A controlled study on the effectiveness of loratadine in combination with flunisolide in the treatment of nonallergic rhinitis with eosinophilia (NARES). Clin Exp Allergy. 1999;29(8):1143-1147. 
31. Braun JJ, Alabert JP, Michel FB, et al. Adjunct effect of loratadine in the treatment of acute sinusitis in patients with allergic rhinitis. Allergy. 1997;52(6):650-655.

32. Haye R, Aanesen JP, Burtin B, Donnelly F, Duby C. The effect of cetirizine on symptoms and signs of nasal polyposis. J Laryngol Otol. 1998;112(11):1042-1046.

33. Mösges R, Klimek L. Azelastine reduces mediators of inflammation in patients with nasal polyps. Allergy Asthma Proc. 1998;19(6): 379-383.

34. Berkowitz RB, Tinkelman DG. Evaluation of oral terfenadine for treatment of the common cold. Ann Allergy. 1991;67(6):593-597.

35. Gaffey MJ, Kaiser DL, Hayden FG. Ineffectiveness of oral terfenadine in natural colds: evidence against histamine as a mediator of common cold symptoms. Pediatr Infect Dis J. 1988;7(3):223-228.

36. Muether PS, Gwaltney JM Jr. Variant effect of first- and secondgeneration antihistamines as clues to their mechanism of action on the sneeze reflex in the common cold. Clin Infect Dis. 2001;33(9): 1483-1488.

37. Gibbs TG, McDonnell KA, Stokes T, Graham AA. Acrivastine in two doses compared with placebo in a multicentre, parallel group study for the treatment of seasonal allergic rhinitis. Br J Clin Pract. 1989;43(1):11-14

38. Howarth PH, Holgate ST. Comparative trial of two non-sedative $\mathrm{H}_{1}$ antihistamines, terfenadine and astemizole, for hay fever. Thorax. 1984;39(9):668-672.

39. Meltzer EO, Storms WW, Pierson WE, et al. Efficacy of azelastine in perennial allergic rhinitis: clinical and rhinomanometric evaluation. J Allergy Clin Immunol. 1988;82(3 Pt 1):447-455.

40. Bousquet J, Gaudaño EM, Palma Carlos AG, Staudinger H. A 12-week, placebo-controlled study of the efficacy and safety of ebastine, 10 and $20 \mathrm{mg}$ once daily, in the treatment of perennial allergic rhinitis. Multicentre Study Group. Allergy. 1999;54(6):562-568.

41. Ratner PH, Lim JC, Georges GC. Comparison of once-daily ebastine $20 \mathrm{mg}$, ebastine $10 \mathrm{mg}$, loratadine $10 \mathrm{mg}$, and placebo in the treatment of seasonal allergic rhinitis. The Ebastine Study Group. J Allergy Clin Immunol. 2000;105(6 Pt 1):1101-1107.

42. Bachert C, Brostoff J, Scadding GK, Tasman J, Stalla-Bourdillon A, Murrieta M. Mizolastine therapy also has an effect on nasal blockade in perennial allergic rhinoconjunctivitis. RIPERAN Study Group. Allergy 1998;53(10):969-975.

43. Bruttmann G, Charpin D, Germouty J, Horak F, Kunkel G, Wittmann G. Evaluation of the efficacy and safety of loratadine in perennial allergic rhinitis. J Allergy Clin Immunol. 1989;83(2 Pt 1):411-416.

44. Meltzer EO, Scheinmann P, Rosado Pinto JE, et al. Safety and efficacy of oral fexofenadine in children with seasonal allergic rhinitis - a pooled analysis of three studies. Pediatr Allergy Immunol. 2004;15(3): 253-260.

45. Van Cauwenberge P, Juniper EF. Comparison of the efficacy, safety and quality of life provided by fexofenadine hydrochloride $120 \mathrm{mg}$, loratadine $10 \mathrm{mg}$ and placebo administered once daily for the treatment of seasonal allergic rhinitis. Clin Exp Allergy. 2000;30(6):891-899.

46. Ciprandi G, Cosentino C, Milanese M, Mondino C, Canonica GW. Fexofenadine reduces nasal congestion in perennial allergic rhinitis. Allergy. 2001;56(11):1068-1070.

47. Howarth PH, Stern MA, Roi L, Reynolds R, Bousquet J. Double-blind, placebo-controlled study comparing the efficacy and safety of fexofenadine hydrochloride (120 and $180 \mathrm{mg}$ once daily) and cetirizine in seasonal allergic rhinitis. J Allergy Clin Immunol. 1999;104(5):927-933.

48. Mansmann HC Jr, Altman RA, Berman BA, et al. Efficacy and safety of cetirizine therapy in perennial allergic rhinitis. Ann Allergy. 1992;68(4):348-353.

49. Nayak AS, Schenkel E. Desloratadine reduces nasal congestion in patients with intermittent allergic rhinitis. Allergy. 2001;56(11): 1077-1080.

50. Simons FE, Prenner BM, Finn A Jr. Efficacy and safety of desloratadine in the treatment of perennial allergic rhinitis. J Allergy Clin Immunol. 2003;111(3):617-622.
51. Leynadier F, Mees K, Arendt C, Pinelli ME. Efficacy and safety of levocetirizine in seasonal allergic rhinitis. Acta Otorhinolaryngol Belg. 2001;55(4):305-312.

52. Bachert C, Bousquet J, Canonica GW, et al. Levocetirizine improves quality of life and reduces costs in long-term management of persistent allergic rhinitis. J Allergy Clin Immunol. 2004;114(4):838-844.

53. Berlin JM, Golden SJ, Teets S, Lehman EB, Lucas T, Craig TJ. Efficacy of a steroid nasal spray compared with an antihistamine nasal spray in the treatment of perennial allergic rhinitis. J Am Osteopath Assoc. 2000;100(11 Suppl):S8-S13.

54. Ortolani C, Foresi A, Di Lorenzo G, et al. A double-blind, placebocontrolled comparison of treatment with fluticasone propionate and levocabastine in patients with seasonal allergic rhinitis. FLNCO2 Italian Study Group. Allergy. 1999;54(11):1173-1180.

55. Lange B, Lukat KF, Rettig K, Holtappels G, Bachert C. Efficacy, costeffectiveness, and tolerability of mometasone furoate, levocabastine, and disodium cromoglycate nasal sprays in the treatment of seasonal allergic rhinitis. Ann Allergy Asthma Immunol. 2005;95(3):272-282.

56. Ratner PH, Hampel FC, Amar NJ, et al. Safety and efficacy of olopatadine hydrochloride nasal spray for the treatment of seasonal allergic rhinitis to mountain cedar. Ann Allergy Asthma Immunol. 2005;95(5):474-479.

57. Meltzer EO, Hampel FC, Ratner PH, et al. Safety and efficacy of olopatadine hydrochloride nasal spray for the treatment of seasonal allergic rhinitis. Ann Allergy Asthma Immunol. 2005;95(6):600-606.

58. Wihl JA, Petersen BN, Petersen LN, Gundersen G, Bresson K, Mygind N. Effect of the nonsedative $\mathrm{H} 1$-receptor antagonist astemizole in perennial allergic and nonallergic rhinitis. J Allergy Clin Immunol. 1985;75(6):720-727.

59. Géhanno P, Deschamps E, Garay E, Baehre M, Garay RP. Vasomotor rhinitis: clinical efficacy of azelastine nasal spray in comparison with placebo. ORL J Otorhinolaryngol Relat Spec. 2001;63(2):76-81.

60. van de Heyning PH, van Haesendonck J, Creten W, Rombaut N. Effect of topical levocabastine on allergic and non-allergic perennial rhinitis. A double-blind study, levocabastine vs placebo, followed by an open, prospective, single-blind study on beclomethasone. Allergy. 1988;43(5):386-391.

61. Berkowitz RB, Connell JT, Dietz AJ, Greenstein SM, Tinkelman DG. The effectiveness of the nonsedating antihistamine loratadine plus pseudoephedrine in the symptomatic management of the common cold. Ann Allergy. 1989;63(4):336-339.

62. Clemens CJ, Taylor JA, Almquist JR, Quinn HC, Mehta A, Naylor GS. Is an antihistamine-decongestant combination effective in temporarily relieving symptoms of the common cold in preschool children? J Pediatr. 1997;130(3):463-466.

63. Hutton N, Wilson MH, Mellits ED, et al. Effectiveness of an antihistaminedecongestant combination for young children with the common cold: a randomized, controlled clinical trial. J Pediatr. 1991;118(1): 125-130.

64. Welch MJ, Meltzer EO, Simons FE. $\mathrm{H}_{1}$-antihistamines and the central nervous system. Clin Allergy Immunol. 2002;17:337-388.

65. Rodrigo GJ, Yañez A. The role of antileukotriene therapy in seasonal allergic rhinitis: a systematic review of randomized trials. Ann Allergy Asthma Immunol. 2006;96(6):779-786.

66. Donnelly AL, Glass M, Minkwitz MC, Casale TB. The leukotriene D4receptor antagonist, ICI 204,219, relieves symptoms of acute seasonal allergic rhinitis. Am J Respir Crit Care Med. 1995;151(6):1734-1739.

67. Pullerits T, Praks L, Skoogh BE, Ani R, Lötvall J. Randomized placebocontrolled study comparing a leukotriene receptor antagonist and a nasal glucocorticoid in seasonal allergic rhinitis. Am J Respir Crit Care Med. 1999;159(6):1814-1818.

68. Knapp HR. Reduced allergen-induced nasal congestion and leukotriene synthesis with an orally active 5-lipoxygenase inhibitor. $N$ Engl J Med. 1990;323(25):1745-1748

69. Philip G, Malmstrom K, Hampel FC, et al. Montelukast for treating seasonal allergic rhinitis: a randomized, double-blind, placebo-controlled trial performed in the spring. Clin Exp Allergy. 2002;32(7):1020-1028. 
70. Meltzer EO, Malmstrom K, Lu S, et al. Concomitant montelukast and loratadine as treatment for seasonal allergic rhinitis: a randomized, placebo-controlled clinical trial. J Allergy Clin Immunol. 2000;105(5): 917-922.

71. Moinuddin R, deTineo M, Maleckar B, Naclerio RM, Baroody FM. Comparison of the combinations of fexofenadine-pseudoephedrine and loratadine-montelukast in the treatment of seasonal allergic rhinitis. Ann Allergy Asthma Immunol. 2004;92(1):73-79.

72. Patel P, Philip G, Yang W, et al. Randomized, double-blind, placebocontrolled study of montelukast for treating perennial allergic rhinitis. Ann Allergy Asthma Immunol. 2005;95(6):551-557.

73. Martin BG, Andrews CP, van Bavel JH, et al. Comparison of fluticasone propionate aqueous nasal spray and oral montelukast for the treatment of seasonal allergic rhinitis symptoms. Ann Allergy Asthma Immunol. 2006;96(6):851-857.

74. Nathan RA, Yancey SW, Waitkus-Edwards K, et al. Fluticasone propionate nasal spray is superior to montelukast for allergic rhinitis while neither affects overall asthma control. Chest. 2005;128(4):1910-1920.

75. Mostafa BE, Abdel Hay H, Mohammed HE, Yamani M. Role of leukotriene inhibitors in the postoperative management of nasal polyps. ORL J Otorhinolaryngol Relat Spec. 2005;67(3):148-153.

76. Ulualp SO, Sterman BM, Toohill RJ. Antileukotriene therapy for the relief of sinus symptoms in aspirin triad disease. Ear Nose Throat J. 1999;78:604-606, 608, 613, passim.

77. Harmanci K. Montelukast: its role in the treatment of childhood asthma. Ther Clin Risk Manag. 2007;3(5):885-892.

78. Bisgaard H. Leukotriene modifiers in pediatric asthma management. Pediatrics. 2001;107(2):381-390.

79. Salvi SS, Krishna MT, Sampson AP, Holgate ST. The anti-inflammatory effects of leukotriene-modifying drugs and their use in asthma. Chest. 2001;119(5):1533-1546.

80. FDA. Leukotriene inhibitors: montelukast (marketed as singulair), zafirlukast (marketed as Accolate), and zileuton (marketed as Zyflo and Zyflo CR). August 28, 2009. Available at: http://www.fda.gov/Safety/ MedWatch/SafetyInformation/SafetyAlertsforHumanMedicalProducts// ucm16624.htm.

81. Singulair (montelukast sodium) [package insert]. Whitehouse Station, NJ: Merck and Co; 2009. Available at: http://www.merck.com/product/ usa/pi_circulars/s/singulair/singulair_pi.pdf. Accessed December 4, 2009.

82. Ramey JT, Bailen E, Lockey RF. Rhinitis medicamentosa. J Investig Allergol Clin Immunol. 2006;16(3):148-155.

83. Scadding GK, Durham SR, Mirakian R, et al. BSACI guidelines for the management of rhinosinusitis and nasal polyposis. Clin Exp Allergy. 2007;38:260-275.

84. Thomas M, Yawn BP, Price D, Lund V, Mullol J, Fokkens W. EPOS Primary Care Guidelines: European Position Paper on the Primary Care Diagnosis and Management of Rhinosinusitis and Nasal Polyps 2007 - a summary. Prim Care Respir J. 2008;17(2):79-89.

85. Selner JC, Koepke JW, Staudenmayer H, et al. Assessment of nasal patency by rhinoscopic measurement of cross sectional nasal airway area: correlation with subjective nasal symptoms. Ann Allergy. 1991;66(1):43-47.

86. Stübner UP, Toth J, Marks B, Berger UE, Burtin B, Horak F. Efficacy and safety of an oral formulation of cetirizine and prolonged-release pseudoephedrine versus xylometazoline nasal spray in nasal congestion. Arzneimittelforschung. 2001;51(11):904-910.

87. Barnes ML, Biallossterski BT, Gray RD, Fardon TC, Lipworth BJ. Decongestant effects of nasal xylometazoline and mometasone furoate in persistent allergic rhinitis. Rhinology. 2005;43:291-295.

88. Mucha SM, deTineo M, Naclerio RM, Baroody FM. Comparison of montelukast and pseudoephedrine in the treatment of allergic rhinitis. Arch Otolaryngol Head Neck Surg. 2006;132(2):164-172.

89. Grosclaude M, Mees K, Pinelli ME, Lucas M, Van de Venne H. Cetirizine and pseudoephedrine retard, given alone or in combination, in patients with seasonal allergic rhinitis. Rhinology. 1997;35(2): $67-73$.
90. Chervinsky P, Nayak A, Rooklin A, Danzig M. Efficacy and safety of desloratadine/pseudoephedrine tablet, 2.5/120 mg two times a day, versus individual components in the treatment of patients with seasonal allergic rhinitis. Allergy Asthma Proc. 2005;26(5):391-396.

91. Caenen M, Hamels K, Deron P, Clement P. Comparison of decongestive capacity of xylometazoline and pseudoephedrine with rhinomanometry and MRI. Rhinology. 2005;43(3):205-209.

92. McCormick DP, John SD, Swischuk LE, Uchida T. A double-blind, placebo-controlled trial of decongestant-antihistamine for the treatment of sinusitis in children. Clin Pediatr (Phila). 1996;35(9):457-460.

93. Taverner D, Latte J. Nasal decongestants for the common cold. Cochrane Database Syst Rev. 2007;24(1):CD001953.

94. Eccles R, Jawad MS, Jawad SS, Angello JT, Druce HM. Efficacy and safety of single and multiple doses of pseudoephedrine in the treatment of nasal congestion associated with common cold. Am J Rhinol. 2005;19(1):25-31.

95. Akerlund A, Klint T, Olén L, Rundcrantz H. Nasal decongestant effect of oxymetazoline in the common cold: an objective dose-response study in 106 patients. J Laryngol Otol. 1989;103(8):743-746.

96. The Combat Meth Act of 2005. US Department of Justice Drug Enforcement Administration, Office of Diversion Control. Available from: http://www.deadiversion.usdoj.gov/meth/q_a.htm\#3_cmea_req. Accessed August 6, 2009

97. Wilson AM, O’Byrne PM, Parameswaran K. Leukotriene receptor antagonists for allergic rhinitis: a systematic review and meta-analysis. Am J Med. 2004;116(5):338-344.

98. Creticos P, Fireman P, Settipane G, Bernstein D, Casale T, Schwartz H. Intranasal budesonide aqueous pump spray (Rhinocort Aqua) for the treatment of seasonal allergic rhinitis. Rhinocort Aqua Study Group. Allergy Asthma Proc. 1998;19(5):285-294.

99. Ratner PH, Paull BR, Findlay SR, et al. Fluticasone propionate given once daily is as effective for seasonal allergic rhinitis as beclomethasone dipropionate given twice daily. J Allergy Clin Immunol. 1992; 90(3 Pt 1):285-291.

100. Berger WE, Nayak AS, Staudinger HW. Mometasone furoate improves congestion in patients with moderate-to-severe seasonal allergic rhinitis. Ann Pharmacother. 2005;39(12):1984-1989.

101. Rosenthal R, Berger W, Bronsky E, et al. Tri-Nasal triamcinolone acetonide nasal spray 200 and 400 micrograms qd versus placebo and Nasacort triamcinolone acetonide nasal aerosol 440 micrograms qd in patients suffering from seasonal allergic rhinitis during the grass season. Am J Rhinol. 1998;12(6):427-433.

102. Kaiser HB, Naclerio RM, Given J, Toler TN, Ellsworth A, Philpot EE. Fluticasone furoate nasal spray: a single treatment option for the symptoms of seasonal allergic rhinitis. J Allergy Clin Immunol. 2007;119(6):1430-1437.

103. Ratner PH, Wingertzahn MA, van Bavel JH, et al. Effectiveness of ciclesonide nasal spray in the treatment of seasonal allergic rhinitis. Ann Allergy Asthma Immunol. 2006;97(5):657-663.

104. Treatment of seasonal allergic rhinitis with once-daily intranasal fluticasone propionate therapy in children. Fluticasone Propionate Collaborative Pediatric Working Group. J Pediatr. 1994;125(4): 628-634.

105. Meltzer EO, Berger WE, Berkowitz RB, et al. A dose-ranging study of mometasone furoate aqueous nasal spray in children with seasonal allergic rhinitis. J Allergy Clin Immunol. 1999;104(1):107-114.

106. Graft D, Aaronson D, Chervinsky P, et al. A placebo- and activecontrolled randomized trial of prophylactic treatment of seasonal allergic rhinitis with mometasone furoate aqueous nasal spray. J Allergy Clin Immunol. 1996;98(4):724-731.

107. Mandl M, Nolop K, Lutsky BN. Comparison of once daily mometasone furoate (Nasonex) and fluticasone propionate aqueous nasal sprays for the treatment of perennial rhinitis. 194-079 Study Group. Ann Allergy Asthma Immunol. 1997;79(4):370-378.

108. Chervinsky P, Kunjibettu S, Miller DL, et al. Long-term safety and efficacy of intranasal ciclesonide in adult and adolescent patients with perennial allergic rhinitis. Ann Allergy Asthma Immunol. 2007;99(1):69-76. 
109. Meltzer EO, Kunjibettu S, Hall N, et al. Efficacy and safety of ciclesonide, 200 microg once daily, for the treatment of perennial allergic rhinitis. Ann Allergy Asthma Immunol. 2007;98(2):175-181.

110. Máspero JF, Rosenblut A, Finn A Jr, Lim J, Wu W, Philpot E. Safety and efficacy of fluticasone furoate in pediatric patients with perennial allergic rhinitis. Otolaryngol Head Neck Surg. 2008;138(1):30-37.

111. Data on file. Kenilworth, New Jersey: Schering Corporation. Protocol No. I96-090.

112. Webb DR, Meltzer EO, Finn AF Jr, et al. Intranasal fluticasone propionate is effective for perennial nonallergic rhinitis with or without eosinophilia. Ann Allergy Asthma Immunol. 2002;88(4):385-390.

113. GlaxoSmithKline. Data on file. Study No. FLN-351. Available from: http://ctr.gsk.co.uk/Summary/fluticasone_propionate/studylist.asp. Accessed August 6, 2009.

114. Meltzer EO, Charous BL, Busse WW, Zinreich SJ, Lorber RR, Danzig MR. Added relief in the treatment of acute recurrent sinusitis with adjunctive mometasone furoate nasal spray. The Nasonex Sinusitis Group. J Allergy Clin Immunol. 2000;106(4):630-637.

115. Meltzer EO, Orgel HA, Backhaus JW, et al. Intranasal flunisolide spray as an adjunct to oral antibiotic therapy for sinusitis. J Allergy Clin Immunol. 1993;92(6):812-823.

116. Nayak AS, Settipane GA, Pedinoff A, et al. Effective dose range of mometasone furoate nasal spray in the treatment of acute rhinosinusitis. Ann Allergy Asthma Immunol. 2002;89(3):271-278.

117. Dolor RJ, Witsell DL, Hellkamp AS, Williams JW Jr, Califf RM, Simel DL; Ceftin and Flonase for Sinusitis (CAFFS) Investigators. Comparison of cefuroxime with or without intranasal fluticasone for the treatment of rhinosinusitis. The CAFFS Trial: a randomized controlled trial. JAMA. 2001;286(24):3097-3105.

118. Barlan IB, Erkan E, Bakir M, Berrak S, Başaran MM. Intranasal budesonide spray as an adjunct to oral antibiotic therapy for acute sinusitis in children. Ann Allergy Asthma Immunol. 1997;78(6):598-601.

119. Yilmaz G, Varan B, Yilmaz T, Gürakan B. Intranasal budesonide spray as an adjunct to oral antibiotic therapy for acute sinusitis in children Eur Arch Otorhinolaryngol. 2000;257(5):256-259.

120. Meltzer EO, Bachert C, Staudinger H. Treating acute rhinosinusitis: comparing efficacy and safety of mometasone furoate nasal spray, amoxicillin, and placebo. J Allergy Clin Immunol. 2005;116(6):1289-1295.

121. Lund VJ, Black JH, Szabó LZ, Schrewelius C, Akerlund A. Efficacy and tolerability of budesonide aqueous nasal spray in chronic rhinosinusitis patients. Rhinology. 2004;42(2):57-62.

122. Holmberg K, Juliusson S, Balder B, Smith DL, Richards DH, Karlsson G. Fluticasone propionate aqueous nasal spray in the treatment of nasal polyposis. Ann Allergy Asthma Immunol. 1997;78(3):270-276.

123. Lund VJ, Flood J, Sykes AP, Richards DH. Effect of fluticasone in severe polyposis. Arch Otolaryngol Head Neck Surg. 1998;124(5): 513-518.

124. Small CB, Hernandez J, Reyes A, et al. Efficacy and safety of mometasone furoate nasal spray in nasal polyposis. J Allergy Clin Immunol 2005;116(6):1275-1281.

125. Stjärne P, Mösges R, Jorissen M, et al. A randomized controlled trial of mometasone furoate nasal spray for the treatment of nasal polyposis. Arch Otolaryngol Head Neck Surg. 2006;132(2):179-185.

126. Keith P, Nieminen J, Hollingworth K, Dolovich J. Efficacy and tolerability of fluticasone propionate nasal drops 400 microgram once daily compared with placebo for the treatment of bilateral polyposis in adults. Clin Exp Allergy. 2000;30(10):1460-1468.

127. Scadding GK. Comparison of medical and surgical treatment of nasal polyposis. Curr Allergy Asthma Rep. 2002;2(6):494-499.

128. Puhakka T, Mäkelä MJ, Malmström K, et al. The common cold: effects of intranasal fluticasone propionate treatment. JAllergy Clin Immunol. 1998;101(6 Pt 1):726-731.

129. Qvarnberg Y, Valtonen H, Laurikainen K. Intranasal beclomethasone dipropionate in the treatment of common cold. Rhinology 2001;39(1):9-12.

130. Flixonase [package insert]. Brentford, Middlesex, UK: GlaxoSmithKline; 2008 .
131. Nasonex [package insert]. Kenilworth, NJ: Schering-Plough Corporation; 2005.

132. Veramyst [package insert]. Research Triangle Park, NC: GlaxoSmithKline; 2007.

133. Rhinocort [package insert]. Wilmington, DE: AstraZeneca LP; 2005.

134. Beconase [package insert]. Research Triangle Park, NC: GlaxoSmithKline; 2005 .

135. Nasacort [package insert]. Bridgewater, NJ: Sanofi-aventis; 2008.

136. Argenti D, Shah B, Heald D. A pharmacokinetic study to evaluate the absolute bioavailability of triamcinolone acetonide following inhalation administration. J Clin Pharmacol. 1999;39(7):695-702.

137. Allen DB. Systemic effects of intranasal steroids: an endocrinologist's perspective. J Allergy Clin Immunol. 2000;106(4 Supp1): S179-S190.

138. Brannan MD, Seiberling M, Cutler DL, Cuss FM, Affrime MB. Lack of systemic activity with intranasal mometasone furoate [abstract]. J Allergy Clin Immunol. 1996;97(1):198.

139. Brannan MD, Herron JM, Affrime MB. Safety and tolerability of once-daily mometasone furoate aqueous nasal spray in children. Clin Ther. 1997;19(6):1330-1339.

140. Skoner DP, Gentile D, Angelini B, Kane R, Birdsall D, Banerji D. The effects of intranasal triamcinolone acetonide and intranasal fluticasone propionate on short-term bone growth and HPA axis in children with allergic rhinitis. Ann Allergy Asthma Immunol. 2003;90(1):56-62.

141. Bachert C, Lukat KF, Lange B. Effect of intranasal fluticasone propionate and triamcinolone acetonide on basal and dynamic measures of hypothalamic-pituitary-adrenal-axis activity in healthy volunteers. Clin Exp Allergy. 2004;34(1):85-90.

142. Skoner DP, Rachelefsky GS, Meltzer EO, et al. Detection of growth suppression in children during treatment with intranasal beclomethasone dipropionate. Pediatrics. 2000;105(2):E23.

143. Schenkel EJ, Skoner DP, Bronsky EA, et al. Absence of growth retardation in children with perennial allergic rhinitis after one year of treatment with mometasone furoate aqueous nasal spray. Pediatrics. 2000;105(2):E22.

144. Minshall E, Ghaffar O, Cameron L, et al. Assessment by nasal biopsy of long-term use of mometasone furoate aqueous nasal spray (Nasonex) in the treatment of perennial rhinitis. Otolaryngol Head Neck Surg. 1998;118(5):648-654.

145. Klossek JM, Laliberté F, Laliberté MF, Mounedji N, Bousquet J. Local safety of intranasal triamcinolone acetonide: clinical and histological aspects of nasal mucosa in the long-term treatment of perennial allergic rhinitis. Rhinology. 2001;39(1):17-22.

146. Holgate ST. Reflections on the mechanism(s) of action of sodium cromoglycate (Intal) and the role of mast cells in asthma. Respir Med. 1989;83(Suppl A):25-31.

147. Ratner PH, Ehrlich PM, Fineman SM, Meltzer EO, Skoner DP. Use of intranasal cromolyn sodium for allergic rhinitis. Mayo Clin Proc. 2002;77(4):350-354.

148. Ogata N, Darby Y, Scadding G. Intranasal lysine-aspirin administration decreases polyp volume in patients with aspirin-intolerant asthma. J Laryngol Otol. 2007;121(12):1156-1160.

149. Meltzer EO, Orgel HA, Bronsky EA, et al. Ipratropium bromide aqueous nasal spray for patients with perennial allergic rhinitis: a study of its effect on their symptoms, quality of life, and nasal cytology. J Allergy Clin Immunol. 1992;90(2):242-249.

150. Kirkegaard J, Mygind N, Mølgaard F, et al. Ordinary and high-dose ipratropium in perennial nonallergic rhinitis. J Allergy Clin Immunol. 1987;79(4):585-590.

151. Atrovent nasal aqueous [package insert]. Auckland, NZ: Boehringer Ingelheim (NZ) Ltd; 2003.

152. Brooks CD, Karl KJ, Francom SF. Oral methylprednisolone acetate (Medrol Tablets) for seasonal rhinitis: examination of dose and symptom response. J Clin Pharmacol. 1993;33(9):816-822.

153. Brooks CD, Titus CR, Heissler CT. Vasoconstrictor and corticosteroid responsive components of allergic nasal mucosal swelling. Ann Allergy. 1988;61(2):151-156. 
154. Hissaria P, Smith W, Wormald PJ, et al. Short course of systemic corticosteroids in sinonasal polyposis: a double-blind, randomized, placebo-controlled trial with evaluation of outcome measures. J Allergy Clin Immunol. 2006;118:128-133.

155. Lacroix JS, Buvelot JM, Polla BS, Lundberg JM. Improvement of symptoms of non-allergic chronic rhinitis by local treatment with capsaicin. Clin Exp Allergy. 1991;21(5):595-600.

156. Eccles R, Jawad MS, Morris S. The effects of oral administration of (-)-menthol on nasal resistance to airflow and nasal sensation of airflow in subjects suffering from nasal congestion associated with the common cold. J Pharm Pharmacol. 1990;42(9):652-654.

157. Wallace DV, Dykewicz, Bernstein DI, et al; for the Joint Task Force on Practice Parameter for Allergy and Immunology. The diagnosis and management of rhinitis: an updated practice parameter. JAllergy Clin Immunol. 2008;122(suppl 2); S1-S84.

158. Harvey R, Hannan SA, Badia L, Scadding G. Nasal saline irrigations for the symptoms of chronic rhinosinusitis. Cochrane Database Syst Rev. 2007;18(3):CD006394.

159. Wang YH, Yang CP, Ku MS, Sun HL, Lue KH. Efficacy of nasal irrigation in the treatment of acute sinusitis in children. Int J Pediatr Otorhinolaryngol. 2009;73(12):1696-1701.

160. Rabago D, Zgierska A, Mundt M, Barret B, Bobula J, Maberry R. Efficacy of daily hypertonic saline nasal irrigation among patients with sinusitis: a randomized controlled trial. J Fam Pract. 2002;51(12); 1049-1055.

161. Ciprandi G, Passalacqua G. Emerging anti-inflammatory agents for allergic rhinitis. Expert Opin Emerg Drugs. 2005;10(4):689-705.

162. Dahl R, Kapp A, Colombo G, et al. Efficacy and safety of sublingual immunotherapy with grass allergen tablets for seasonal allergic rhinoconjunctivitis. J Allergy Clin Immunol. 2006;118(2):434-440.

163. Wilson DR, Lima MT, Durham SR. Sublingual immunotherapy for allergic rhinitis: systematic review and meta-analysis. Allergy. 2005;60(1):4-12.

164. Durham SR, Walker SM, Varga EM, et al. Long-term clinical efficacy of grass-pollen immunotherapy. $N$ Engl J Med. 1999;341(7): $468-475$.

165. D’Amato G, Kordash TR, Liccardi G, Lobefalo G, Cazzola M, Freshwater LL. Immunotherapy with Alpare in patients with respiratory allergy to Parietaria pollen: a two year double-blind placebo-controlled study. Clin Exp Allergy. 1995;25(2):149-158.

166. Varney VA, Gaga M, Frew AJ, Aber VR, Kay AB, Durham SR. Usefulness of immunotherapy in patients with severe summer hay fever uncontrolled by antiallergic drugs. BMJ. 1991;302(6771):265-269.

167. Van Deusen MA, Angelini BL, Cordoro KM, Seiler BA, Wood L, Skoner DP. Efficacy and safety of oral immunotherapy with short ragweed extract. Ann Allergy Asthma Immunol. 1997;78(6):573-580.

168. Durham SR, Riis B. Grass allergen tablet immunotherapy relieves individual seasonal eye and nasal symptoms, including nasal blockage. Allergy. 2007;62(8):954-957.

169. Calderon MA, Birk AO, Andersen JS, Durham SR. Prolonged preseasonal treatment phase with Grazax sublingual immunotherapy increases clinical efficacy. Allergy. 2007;62(8):958-961.

170. Didier A, Malling HJ, Worm M, et al. Optimal dose, efficacy, and safety of once-daily sublingual immunotherapy with a 5-grass pollen tablet for seasonal allergic rhinitis. J Allergy Clin Immunol. 2007;120(6):1338-1345.

171. Tonnel AB, Scherpereel A, Douay B, et al. Allergic rhinitis due to house dust mites: evaluation of the efficacy of specific sublingual immunotherapy. Allergy. 2004;59(5):491-497.

172. Kemker B, Liu X, Gungor A, Moinuddin R, Corey JP. Effect of nasal surgery on the nasal cavity as determined by acoustic rhinometry. Otolaryngol Head Neck Surg. 1999;121(5):567-571.

173. Konstantinidis I, Triaridis S, Triaridis A, Karagiannidis K, Kontzoglou G. Long term results following nasal septal surgery. Focus on patients' satisfaction. Auris Nasus Larynx. 2005;32(4):369-374.

174. Stewart MG, Smith TL, Weaver EM, et al. Outcomes after nasal septoplasty: results from the Nasal Obstruction Septoplasty Effectiveness (NOSE) study. Otolaryngol Head Neck Surg. 2004;130(3):283-290.
175. Murakami C. Nasal valve collapse. Ear Nose Throat J. 2004;83(3): 163-164.

176. Hol MK, Huizing EH. Treatment of inferior turbinate pathology: a review and critical evaluation of the different techniques. Rhinology. 2000;38(4):157-166.

177. Cavaliere M, Mottola G, Iemma M. Comparison of the effectiveness and safety of radiofrequency turbinoplasty and traditional surgical technique in treatment of inferior turbinate hypertrophy. Otolaryngol Head Neck Surg. 2005;133(6):972-978.

178. Huang TW, Cheng PW. Changes in nasal resistance and quality of life after endoscopic microdebrider-assisted inferior turbinoplasty in patients with perennial allergic rhinitis. Arch Otolaryngol Head Neck Surg. 2006;132(9):990-993.

179. Wexler D, Braverman I. Partial inferior turbinectomy using the microdebrider. J Otolaryngol. 2005;34(3):189-193.

180. Lee JY, Lee JD. Comparative study on the long-term effectiveness between coblation- and microdebrider-assisted partial turbinoplasty. Laryngoscope. 2006;116(5):729-734.

181. Dawes PJ. The early complications of inferior turbinectomy. J Laryngol Otol. 1987;101(11):1136-1139.

182. Kim YK, Kang JH, Yoon KS. Acoustic rhinometric evaluation of nasal cavity and nasopharynx after adenoidectomy and tonsillectomy. Int J Pediatr Otorhinolaryngol. 1998;44(3):215-220.

183. Vandenberg SJ, Heatley DG. Efficacy of adenoidectomy in relieving symptoms of chronic sinusitis in children. Arch Otolaryngol Head Neck Surg. 1997;123(7):675-678.

184. Bhattacharyya N. Symptom outcomes after endoscopic sinus surgery for chronic rhinosinusitis. Arch Otolaryngol Head Neck Surg. 2004;130(3):329-333.

185. Numminen J, Dastidar P, Rautiainen M. Influence of sinus surgery in rhinometric measurements. J Otolaryngol. 2004;33(2):98-103.

186. Smith TL, Mendolia-Loffredo S, Loehrl TA, Sparapani R, Laud PW, Nattinger AB. Predictive factors and outcomes in endoscopic sinus surgery for chronic rhinosinusitis. Laryngoscope. 2005;115(12): 2199-2205.

187. Sipilä J, Antila J, Suonpää J. Pre- and postoperative evaluation of patients with nasal obstruction undergoing endoscopic sinus surgery. Eur Arch Otorhinolaryngol. 1996;253(4-5):237-239.

188. Bunnag C, Jareoncharsri P, Wong EC. A doubleblind comparison of nasal budesonide and oral astemizole for the treatment of perennial rhinitis. Allergy. 1992;47(4 Pt 1):313-317.

189. Simpson RJ. Budesonide and terfenadine, separately and in combination, in the treatment of hay fever. Ann Allergy. 1994;73(6): 497-502.

190. Brooks CD, Francom SF, Peel BG, Chene BL, Klott KA. Spectrum of seasonal allergic rhinitis symptom relief with topical corticoid and oral antihistamine given singly or in combination. Am J Rhinol. 1996;10:193-199.

191. Bernstein DI, Creticos PS, Busse WW, Cohen R, Graft DF, Howland WC, et al. Comparison of triamcinolone acetonide nasal inhaler with astemizole in the treatment of ragweedinduced allergic rhinitis. J Allergy Clin Immunol. 1996;97(3):749-755.

192. Schoenwetter W, Lim J. Comparison of intranasal triamcinolone acetonide with oral loratadine for the treatment of patients with seasonal allergic rhinitis. Clin Ther. 1995;17(3):479-492.

193. Vervloet D, Charpin D, Desfougeres JL. Intranasal fluticasone once daily compared with once daily cetirizine in the treatment of seasonal allergic rhinitis. Clin Drug Invest. 1997;13:291-298.

194. Bronsky EA, Dockhorn RJ, Meltzer EO, Shapiro G, Boltansky H, LaForce $\mathrm{C}$, et al. Fluticasone propionate aqueous nasal spray compared with terfenadine tablets in the treatment of seasonal allergic rhinitis. J Allergy Clin Immunol. 1996;97(4):915-921.

195. Munch EP, Soborg M, Norreslet TT, Mygind N. A comparative study of dexchlorpheniramine maleate sustained release tablets and budesonide nasal spray in seasonal allergic rhinitis. Allergy. 1983;38(7):517-524.

196. Géhanno P, Desfougeres JL. Fluticasone propionate aqueous nasal spray compared with oral loratadine in patients with seasonal allergic rhinitis. Allergy. 1997;52(4):445-450. 
197. Juniper EF, Kline PA, Hargreave FE, Dolovich J. Comparison of beclomethasone dipropionate aqueous nasal spray, astemizole, and the combination in the prophylactic treatment of ragweed pollen-induced rhinoconjunctivitis. J Allergy Clin Immunol. 1989;83(3):627-633.

198. Darnell R, Pecoud A, Richards DH. A double-blind comparison of fluticasone propionate aqueous nasal spray, terfenadine tablets and placebo in the treatment of patients with seasonal allergic rhinitis to grass pollen. Clin Exp Allergy. 1994;24(12):1144-1150.

199. Beswick KB, Kenyon GS, Cherry JR. A comparative study of beclomethasone dipropionate aqueous nasal spray with terfenadine tablets in seasonal allergic rhinitis. Curr Med Res Opin. 1985;9(8):560-567.

200. Wood SF. Oral antihistamine or nasal steroid in hay fever; a doubleblind double-dummy comparative study of once daily oral astemizole vs twice daily nasal beclomethasone dipropionate. Clin Allergy. 1986;16(3):195-201.
201. Robinson AC, Cherry JR, Daly S. Double-blind crossover trial comparing beclomethasone dipropionate and terfenadine in perennial rhinitis. Clin Exp Allergy. 1989;19(5):569-573.

202. Davies RJ, Lund VJ, Harten-Ash VJ. The effect of intranasal azelastine and beclomethasone on the symptoms and signs of nasal allergy in patients with perennial allergic rhinitis. Rhinology. 1993;31(4):159-164.

203. Di Lorenzo G, Gervasi F, Drago A, et al. Comparison of the effects of fluticasone propionate, aqueous nasal spray and levocabastine on inflammatory cells in nasal lavage and clinical activity during the pollen season in seasonal rhinitis. Clin Exp Allergy. 1999;29(10):1367-1377.

204. Stern MA, Wade AG, Ridout SM, Cambell LM. Nasal budesonide offers superior symptom relief in perennial allergic rhinitis in comparison to nasal azelastine. Ann Allergy Asthma Immunol. 1998;81(4):354-358.
International Journal of General Medicine

\section{Publish your work in this journal}

The International Journal of General Medicine is an international peer-reviewed open-access journal that focuses on general and internal medicine, pathogenesis, epidemiology, diagnosis, monitoring and treatment protocols. The journal is characterized by the rapid reporting of reviews, original research and clinical studies across all disease areas.

\section{Dovepress}

A key focus is the elucidation of disease processes and management protocols resulting in improved outcomes for the patient.The manuscript management system is completely online and includes a very quick and fair peer-review system. Visit http://www.dovepress.com/ testimonials.php to read real quotes from published authors.

Submit your manuscript here: http://www.dovepress.com/international-journal-of-general-medicine-journal 